\title{
MODELAGEM APLICADA NA ESTIMATIVA DE VAZÃO DE UMA BACIA HIDROGRÁFICA NO SUDOESTE DE GOIÁS, CERRADO BRASILEIRO
}

\author{
Wellmo dos Santos Alves \\ Universidade Federal de Jataí, Jataí, Goiás, Brasil \\ wellmoagro2@gmail.com \\ Alécio Perini Martins \\ Universidade Federal de Jataí, Jataí, Goiás, Brasil \\ alecioperini@ufg.br \\ Raina Santos Ferreira \\ Universidade de Brasília, Brasília, Distrito Federal, Brasil \\ rainasanfer@gmail.com
}

\begin{abstract}
RESUMO
É fundamental uma gestão dos recursos hídricos que integre os diferentes usuários e que garanta, com vistas ao desenvolvimento sustentável, a disponibilidade hídrica para toda a sociedade. Assim, torna-se importante a geração de dados para subsidiar o planejamento e a gestão de bacias hidrográficas $(\mathrm{BH})$ de forma condizente com o desenvolvimento ecologicamente equilibrado. Considerando o exposto, objetivou-se estimar a vazão hídrica em sete pontos na BH do Rio Verdinho, no Sudoeste de Goiás, Cerrado Brasileiro. Foi usado o modelo Soil and Water Assessment Tool (SWAT), sendo a modelagem realizada no ArcSWAT e calibração no SWAT-Calibration and Uncertainty Proceduresfoi (SWATCUP), com uso do algoritmo Sequential Uncertainty Fitting para análise de sensibilidade. Os resultados pós processo de calibração $\left(N S=0,53, R^{2}=0,83\right.$ e PBIAS=-22,5) evidenciam que o modelo SWAT simulou de forma satisfatória a vazão, sendo observado que o SWAT-CUP teve dificuldade de ajustar as variáveis terrestres evapotranspiração e escoamento de base. Esse estudo servirá de base para outras pesquisas em ambientes de Cerrado, principalmente na região Sudoeste de Goiás, onde não são observados estudos com o referido modelo. Os resultados também subsidiarão ações e políticas públicas efetivas e eficientes na gestão hídrica local e regional.
\end{abstract}

Palavras-chave: Geotecnologias. Modelagem hidrológica. Recursos hídricos. SWAT. SWAT-CUP.

\section{MODELING APPLIED TO THE FLOW ESTIMATE OF A HYDROGRAPHIC BASIN IN THE SOUTHWESTERN OF GOIÁS, BRAZILIAN CERRADO}

\begin{abstract}
Water resource management is essential for the integration of different users and water availability for the whole society in a sustainable way. Thus, it is important to generate data to support the planning and the watershed management in an ecologically balanced way. Considering the above, the objective of this research is to estimate the water flow in seven points of the Rio Verdinho watershed, in the Goiás' southwest region, Brazilian Cerrado. The Soil and Water Assessment Tool (SWAT) model was used for this study, the modeling was performed in ArcSWAT and the calibration was made in SWAT-Calibration and Uncertainty Procedures (SWAT-CUP), using the Sequential Uncertainty Fitting algorithm for sensitivity analysis. The results after the calibration process $\left(\mathrm{NS}=0.53, \mathrm{R}^{2}=0.83\right.$ and PBIAS $=-22.5$ ) show that the SWAT model satisfactorily simulated the flow, being observed that the SWAT. CUP had difficulty adjusting the terrestrial variables evapotranspiration and base flow. This study will serve as a support for others researchers in Cerrado environments, mainly in the Goiás' southwest region, where studies with the referred model are not observed. The results will also subsidize the effectiveness and efficiency of the public actions and policies in the local and regional water management.
\end{abstract}

Keywords: Geotechnology. Hydrological modeling. Water resources. SWAT. SWAT-CUP.

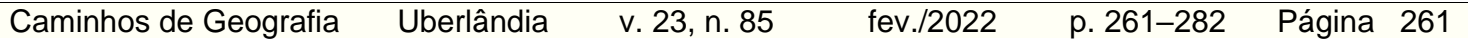




\section{INTRODUÇÃO}

O bioma Cerrado Brasileiro é um dos hotspots ambientais mundiais devido à sua biodiversidade e em decorrência de graves impactos antrópicos que tem sofrido. Em seus diferentes ecossistemas internos - variando de pastagens a florestas tropicais secas - e áreas de transição para todos os outros principais biomas brasileiros contêm altos níveis de biodiversidade, bem como endemismo (FERREIRA et al., 2011). Esse bioma está inserido na bacia hidrográfica (BH) do rio Paranaíba (da qual a BH do Rio Verdinho é afluente), que apresenta constante desenvolvimento econômico, com destaque na produção agropecuária, sendo bastante dependente de seus recursos hídricos. Estes são usados principalmente para consumo, irrigação, produção de energia elétrica, produção animal e nos processos agroindustriais.

Nas últimas décadas, o crescimento populacional tem resultado no aumento da demanda por recursos naturais e na ocupação de áreas para expansão da agricultura e pecuária. Nesse cenário, novos usos da terra têm sido intensificados, muitas vezes sem avaliações prévias de possíveis degradações ambientais causadas pela exploração intensiva. Como consequência da expansão das atividades agrícolas, surgem problemas que impactam diretamente a qualidade e quantidade de água disponível, considerando-se tanto os usos atuais como os futuros (ANA, 2013; OLIVEIRA et al., 2017; LOPES et al., 2020).

O desequilíbrio entre a demanda e a disponibilidade de água tem levado à necessidade de desenvolver uma gestão dos recursos hídricos mais eficiente. Devido a esse desequilíbrio, começam a surgir conflitos entre os diferentes setores, tornando-se fundamental uma gestão que integre os diferentes usuários e que garanta, com vistas ao desenvolvimento sustentável, a disponibilidade desse recurso para toda a sociedade (FERREIRA e UAGODA, 2017). Os impactos das ações antrópicas nos componentes hidrológicos devem ser considerados pelos formuladores de políticas envolvidos no planejamento do uso e cobertura da terra em bacias hidrográficas para o manejo sustentável e efetivo dos recursos hídricos e preparo de planos de uso ambientalmente positivos (SERTEL et al., 2019; AWOTWI et al., 2019). Nesse sentido, os modelos hidrológicos se tornaram uma ferramenta importante para a avaliação dos processos hídricos. Pode-se usar a modelagem nos estudos de avaliação ambiental, para conjecturar cenários futuros, estimar a magnitude das alterações a serem causadas pelas atividades estabelecidas ou outras a serem desenvolvidas, tendo em vista atender às diversas demandas (ABBASPOUR et al., 2015; FERREIRA e UAGODA, 2017; AWOTWI et al., 2019; PINIEWSKI; BIEGER; MEHDI, 2019; MARTINS et al., 2020).

A atual filosofia de modelagem requer que os modelos sejam descritos de maneira transparente; e que a calibração, validação, sensibilidade e análise de incerteza sejam realizadas rotineiramente como parte do trabalho de modelagem. Como a calibração é "condicional" (isto é, condicionada na estrutura do modelo, entradas do modelo, suposições do analista, algoritmo de calibração, dados de calibração, etc.) e não exclusivamente determinada, a análise de incerteza é essencial para avaliar a força de um modelo calibrado (ABBASPOUR et al., 2015). Um modelo hidrológico com alto desempenho, que é utilizado em muitos países do mundo e pode disponibilizar dados representativos para o planejamento e gestão de bacias hidrográficas, é o Soil and Water Assessment Tool (SWAT) (ARNOLD et al., 1998), o qual demonstrou seus pontos fortes nos aspectos especificados acima (ABBASPOUR et al., 2015).

Embora o modelo SWAT seja um simulador hidrológico de base física, ele possui muitas variáveis que não podem ser medidas diretamente no campo, mas devem ser obtidas por meio de um processo de calibração de modelo. A calibração do modelo é, portanto, uma tarefa essencial para obter os valores ideais das variáveis, que combinam as simulações com as observações, tanto quanto possível (LETA; GRIENSVEN; BAUWENSFORAM, 2016). Devido ao grande número de variáveis no processo de modelagem, a parametrização e calibração do modelo tornam-se complicadas (ARNOLD et al., 2012), exigindo do modelador melhor compreensão sobre a relação entre variáveis de entrada e processos hidrológicos.

Diversas técnicas de calibração foram desenvolvidas para o modelo SWAT, incluindo procedimentos de calibração manual e automatizados (ARNOLD et al., 2012). O Soil and Water Assessment Tool Calibration and Uncertainty Proceduresfoi (SWAT-CUP) (ABBASPOUR et al., 2007) desenvolvido para calibração do modelo SWAT, sendo observado na literatura como um aplicativo com ótimo desempenho nesse processo. É importante destacar que é observada, na literatura sobre modelagem com SWAT, a ênfase à fase aquática (calibração de vazão e sedimento), não considerando a fase terrestre (calibração do balanço hídrico). Entretanto, conforme Zhang et al. (2015); Ferreira e Uagoda 
(2017); a calibração das duas fases é importante para o bom funcionamento do modelo SWAT, pois a partir de uma análise conjunta é possível perceber os erros e os acertos no processo de modelagem.

Assim, considerando ainda a importância da BH do Rio Verdinho, no Sudoeste de Goiás, Cerrado Brasileiro, para o abastecimento público de água da população urbana rio-verdense (projeto em fase de implementação para captação de aproximadamente 794,4 L.s. $^{-1}$ ), sendo fonte estratégica para atender a demanda de aproximadamente 235.647 pessoas (estimativa populacional do Instituto Brasileiro de Geografia e Estatística - IBGE, 2019), objetivou-se estimar a vazão hídrica em sete pontos estrategicamente planejados na referida bacia, por meio do modelo SWAT, no intuito de entender o escoamento superficial e disponibilizar dados técnico-científicos sobre essa unidade hidrográfica. Ressalta-se que há poucos estudos sobre modelagem com o SWAT no Cerrado Brasileiro (exemplos, Castro et al., 2016; Ferreira e Uagoda, 2017; Oliveira et al., 2019; Serrão et al., 2020) e não são observadas pesquisas com esse modelo na BH em questão e no Sudoeste de Goiás.

\section{MATERIAL E MÉTODOS}

\section{Localização da área de estudo}

A BH do Rio Verdinho é de 154.430,19 há, localizada nos municípios de Rio Verde (GO) e Santo Antônio da Barra, no Sudoeste de Goiás, Cerrado Brasileiro (Figura 1). Encontra-se entre as coordenadas geográficas $17^{\circ} 29^{\prime} 53,33^{\prime \prime S} / 50^{\circ} 31^{\prime} 34,73^{\prime \prime O}$ e 17³3'57,20"S/51⒉29'14,36"O, no domínio dos chapadões centrais recobertos por cerrados, cerradões e formações campestres, com remanescentes localizados principalmente entre os vales fluviais na forma de matas de galeria e ciliar.

Figura 1 - Sudoeste de Goiás, Cerrado Brasileiro: Localização da bacia hidrográfica do Rio Verdinho

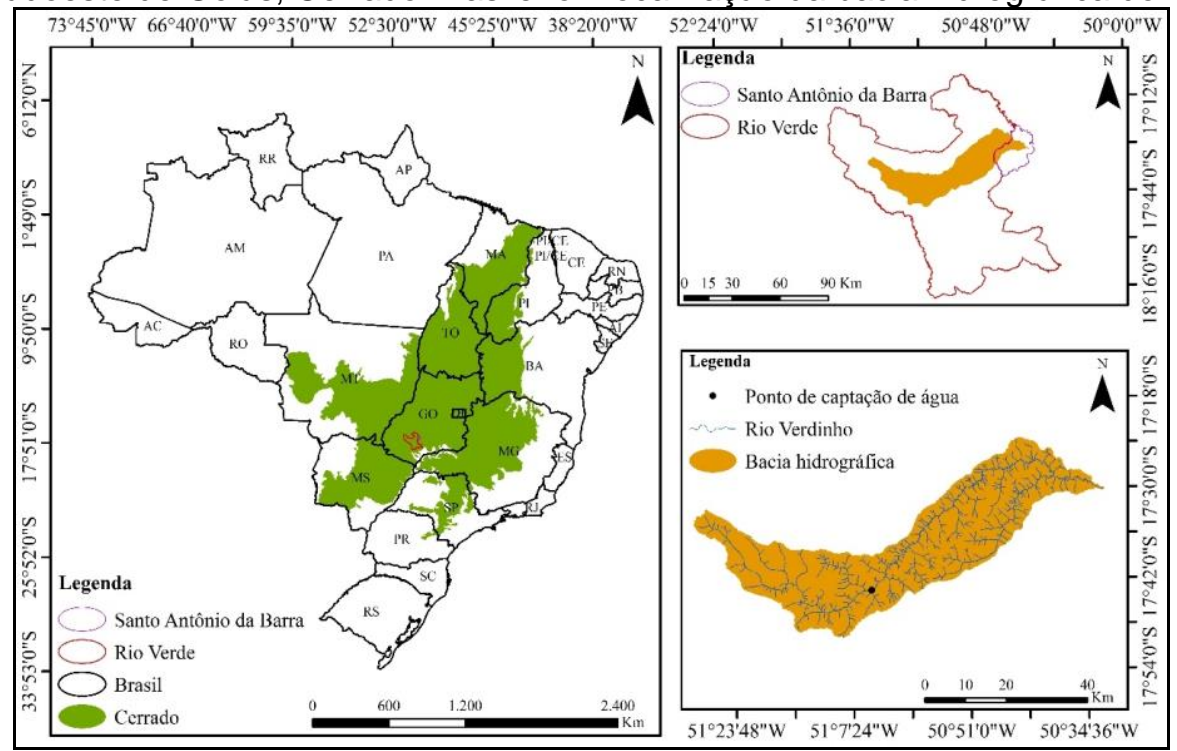

Elaborado no Sistema de Coordenadas Geográficas, Sirgas 2000 e Zona 22S.

Fonte: Organizado pelos autores a partir de Bases de dados disponibilizadas pelo SIEG (2018).

\section{O modelo SWAT}

O SWAT é um modelo de base física, semi-distribuído e contínuo no tempo, que foi desenvolvido pelo Department of Agriculture e Texas A \& M University EUA em Temple, para simular o impacto da mudança do uso e cobertura da terra em diferentes escalas de bacias hidrográficas (ARNOLD et al., 2012). É um código-fonte aberto (ABBASPOUR et al., 2015). Para reproduzir as condições reais, o modelo necessita de dados de entrada sobre as características físicas e climáticas da bacia hidrográfica. Estas especificidades permitem simular diferentes processos físicos (evaporação, infiltração, escoamento superficial, subsuperficial e subterrâneo) (FERREIRA e UAGODA, 2017; SILVA; HENRIQUE; CAZÉ, 2018). 
O SWAT faz a compartimentação da bacia hidrográfica baseado no modelo digital do terreno (MDT) que representa as condições topográficas de declividade e as formas do relevo, associadas às informações pedológicas e de uso e cobertura da terra. As sub-bacias são divididas em unidades de resposta hidrológica (URHs), mantendo as variáveis espacialmente distribuídos com características homogêneas que representam a heterogeneidade dos fatores que influenciam o comportamento hidrológico (RODRIGUES et al., 2015; KRYSANOVA e WHITE, 2015; SILVA; HENRIQUE; CAZÉ, 2018).

O modelo SWAT distingue os fenômenos hidrológicos que ocorrem na bacia hidrográfica em duas partes. A primeira é a fase terrestre do ciclo hidrológico e a segunda é a fase aquática (FERREIRA e UAGODA, 2017). Os processos da fase terrestre são calculados com base na equação do balanço hídrico e consideram as variáveis: precipitação pluviométrica, evapotranspiração, escoamento superficial, infiltração, armazenamento de solo, fluxo lateral, recarga de água subterrânea e fluxo de água subterrânea. Na fase de água, o escoamento, bem como os rendimentos de sedimentos e produtos químicos agrícolas de todas as URHs dentro de uma sub-bacia, são somados e entram no alcance principal da sub-bacia, onde são encaminhados por meio da rede de canais para a saída da unidade hidrográfica.

O SWAT é composto por diversas equações que descrevem o ciclo hidrológico, sendo que no processo para estimar o escoamento superficial, o modelo utiliza equações com base no balanço hídrico. O modelo matemático do balanço hídrico pode ser expresso pela seguinte Equação (E1), conforme Arnold et al. (1998):

$$
\left(S W_{\mathrm{t}}\right)=S W+\sum_{\mathrm{t}=1}^{\mathrm{t}}\left(R_{\mathrm{i}}-Q_{\mathrm{i}}-E T_{\mathrm{i}}-P_{\mathrm{i}}-Q R_{\mathrm{i}}\right)
$$

Na qual: SWt é a quantidade final de água no solo (mm); t, o tempo (dias); Ri, a precipitação do dia $(\mathrm{mm})$; Qi, o escoamento superficial no dia $(\mathrm{mm})$; ETi, a evapotranspiração no dia $(\mathrm{mm}) ; \mathrm{Pi}$, a percolação $(\mathrm{mm})$, ou seja a quantidade de água presente na zona vadosa do solo no dia; e QRi, o fluxo de retorno $(\mathrm{mm})$.

\section{Bases de dados}

Os dados para geração e organização das bases de entrada no modelo SWAT foram:

a) Modelo Digital de Elevação (MDE), resolução de $30 \mathrm{~m}$, elaborado e disponibilizado pelo Instituto Nacional de Pesquisa Espacial (INPE, 2019);

b) Imagens referentes à Grade Sentinel Brasil, 22KDF/22kKEF, com resolução de $10 \mathrm{~m} \times 10 \mathrm{~m}$, de outubro/2016, da constelação de satélites Sentinel/Sensor MultiSpectral Instrument (MSI) (European Space Agency - ESA, 2019) e Comissão Europeia, disponibilizada pela Amazon S3 (2018);

c) Mapa de Solos do Plano Diretor da Bacia do Rio Paranaíba, na escala 1:250.000, elaborado pela Universidade Federal de Viçosa (UFV, 2005)/Fundação Rural Minas (RURALMINAS, 2005), Superintendência de Geologia e Mineração de Goiás (SGM - GO) (2005)/Secretaria de Indústria e Comércio de Goiás (SIC - GO, 2005), disponibilizado pelo SIEG (2018);

d) Dados de precipitação pluviométrica, em mm, compilados da página HidroWeb sob a gestão da Agencia Nacional de Águas (ANA, 2018), observados de um período de 20 anos (1997 a 2016) por meio das estações 01750003 Ponte Rio Verdão, 01750004 Ponte Rodagem, 01750008 Fazenda Paraíso, 01751001 Ponte Rio Doce e 01751004 Montividiu;

e) Dados climáticos da estação climatológica 83470 Rio Verde foram compilados do Banco de Dados Meteorológico para Ensino e Pesquisa (BDMEP, 2019), observados de um período de 20 anos (1997 a 2016); e

f) Dados de vazão (1997 a 2016), em m³. $\mathrm{s}^{-1}$, compilados da página HidroWeb sob a gestão da ANA (2018), observados por meio da estação 60785005 Fazenda Paraíso. 


\section{Processamento e organização dos dados de entrada no modelo}

A parte de geoprocessamento foi realizada no software ArcGIS 10.6.1 ${ }^{\circledR}$ (ESRI, 2019) licenciado para o Laboratório de Geoinformação da Universidade Federal de Goiás/Regional de Jataí. Os mapas foram elaborados no Sistema de Coordenadas Projetadas: Sistema de Referência Geocêntrico para as Américas (Sirgas) 2000, projeção Universal Transversa de Mercator (UTM) e Zona 22 Sul (S).

É importante ressaltar que as variáveis tabeladas de entrada no processo de modelagem possuem valores predeterminados no banco de dados do modelo, estimados a partir de estudos realizados nos Estados Unidos da América. No intuito de melhor reproduzir as características da área de estudo, muitas variáveis foram substituídas por valores obtidos a partir de estudos no Brasil.

Para a geração do mapa de uso e cobertura da terra foram usadas as bandas (B) B2 (azul), B3 (verde) e B4 (vermelho) e B8 (infravermelho próximo), sendo a classificação realizada por meio do algoritmo Interactive Supervised Classification. A legenda preliminar foi assim definida: agricultura, pastagem, água/represa, eucalipto, campo sujo, cerrado/cerradão, mata ciliar/galeria, construção rural/chácara, via pavimentada, solo exposto. Os erros observados na classificação da imagem foram corrigidos de forma manual, no intuito de obter melhor representatividade da área de estudo. Para avaliar a qualidade da classificação, foram obtidas amostras de validação, de forma semiautomática e aleatória, a partir da imagem de satélite Sentinel-2/Sensor MSI, imagens de alta resolução disponibilizadas pela Google por meio do aplicativo Google Earth Pro (GOOGLE, 2016) e, ainda, observações in loco (trabalho de campo). Realizou-se a análise entre o mapa de uso e cobertura da terra com as amostras de validação para obtenção da matriz de confusão. A partir desta matriz foi calculado o Índice Kappa (COHEN, 1960) por meio da Equação 2 (E2) observada em Figueiredo e Vieira (2007). O valor obtido foi comparado com a classificação de Landis e Koch (1977) apresentadas no Quadro 1.

$$
K=\left(n * \sum_{i=1}^{e} X_{\mathrm{ii}}-\sum_{\mathrm{i}=1}^{e} X_{\mathrm{i}+} * X_{+\mathrm{i}}\right) /\left(n^{2}-\sum_{\mathrm{i}=1}^{e} X_{\mathrm{i}+} * X_{+\mathrm{i}}\right)
$$

$\mathrm{Na}$ qual: K é uma estimativa do coeficiente Kappa; $\mathrm{n}$, o número total de amostras; c, o número total de classes; $x_{i i}$, o valor na linha i e coluna $i$, ou seja, o valor da diagonal da matriz de confusão, de forma descendente; $\mathrm{x}_{\mathrm{i}+}$, a soma da linha $\mathrm{i}$; e $\mathrm{x}_{+\mathrm{i}}$, a soma da coluna i da matriz de confusão.

Quadro 1 - Qualidade da classificação conforme intervalos do Índice Kappa

\begin{tabular}{|c|c|}
\hline Valor Kappa & Qualidade da classificação \\
\hline$<0,00$ & Péssima \\
\hline $0,00-0,20$ & Ruim \\
\hline $0,20-0,40$ & Razoável \\
\hline $0,40-0,60$ & Boa \\
\hline $0,60-0,80$ & Muito Boa \\
\hline $0,80-1,00$ & Excelente \\
\hline
\end{tabular}

Foi obtido Índice Kappa de 0,94, sendo a classificação considerada ótima. As categorias de uso e cobertura foram agricultura $(53,84 \%)$, pastagem $(19,04 \%)$, mata ciliar/galeria $(11,14 \%)$, cerrado/cerradão $(10,53 \%)$, campo sujo $(3,89 \%)$, silvicultura $(0,77 \%)$, construção rural $(0,44 \%)$, solo exposto $(0,17 \%)$, rodovia pavimentada $(0,17 \%)$ e água/represa $(0,01 \%)$, totalizando $15.4430,19$ ha (Figura 2). Os dados tabelados de entrada utilizados sobre as variáveis relacionadas ao uso e cobertura da terra foram compilados do site do modelo Soil \& Water Assessment Tool (AGRICULTURAL..., 2019), sendo alteradas variáveis utilizadas para quantificar o desenvolvimento foliar das plantas considerando as características para o clima local. As variáveis modificadas foram para: agricultura (BLAI de 3 alterado para 5 e DLAI de 0,64 alterado para 0,80) (ARROIO JUNIOR, 2016); eucalipto (FRGRW1 de 0,10 alterado para 0,16, LAIMX1 de 0,15 alterado para 0,20, FRGRW2 de 0,50 alterado para 0,60 e LAIMX2 de 0,75 alterado para 0,61); vegetação nativa (todos os valores de BLAl foram alterados para 6), conforme Almeida e Soares (2003). Para as áreas construção 
rural/chácara foram usados os dados relacionados à área residencial média/baixa densidade; rodovia asfaltada, os dados para via pavimentada; e para solo exposto, os dados para via não pavimentada.

A partir do Mapa de Solos do Plano Diretor da Bacia do Rio Paranaíba foi elaborado o mapa de solos da área de estudo. $\mathrm{Na} \mathrm{BH}$ do Rio Verdinho é predominante a classe de Latossolo Vermelho Distrófico $(79,46 \%)$, a segunda maior classe é de Nitossolo Vermelho Distrófico $(8,86 \%)$, em seguida e em ordem decrescente são observadas as classes de Cambissolo Háplico Distrófico (4,40\%), Gleissolo Háplico Distrófico (3,79\%), Argissolo Vermelho Distrófico (2,77\%) e Neossolo Litólico Distrófico $(0,72 \%)$. Sobre a tabela de entrada no modelo SWAT relacionada aos tipos de solos, foram usados os valores observados em Lima et al (2013) para Latossolo, Cambissolo e Gleissolo, por Baldissera (2005) para Nitossolo e Argissolo, e por Medeiros e Silva (2014) para Neossolo Litólico, conforme características local. A classificação da declividade foi realizada diretamente no ArcSWAT a partir do MDE, com base na classificação de Santos et al. (2013), buscando caracterizar o relevo para melhor detalhar a bacia hidrográfica por meio das URHs. As cinco classes de declividade de entrada no modelo hidrológico foram de 0 a $3 \%$, de 3 a $8 \%$, de 8 a $20 \%$, de 20 a $45 \%$ e de 45 a $69 \%$, sendo que essas classes correspondem a $28,22 \%, 49,40 \%, 20,66 \%, 1,69 \%$ e $0,04 \%$, respectivamente, da área total de estudo (Figura 2).

Figura 2 - Sudoeste de Goiás, Cerrado Brasileiro: Produtos cartográficos sobre o uso e cobertura da terra, os solos e a declividade usados no processo de modelagem da bacia hidrográfica do Rio

Verdinho, 2019

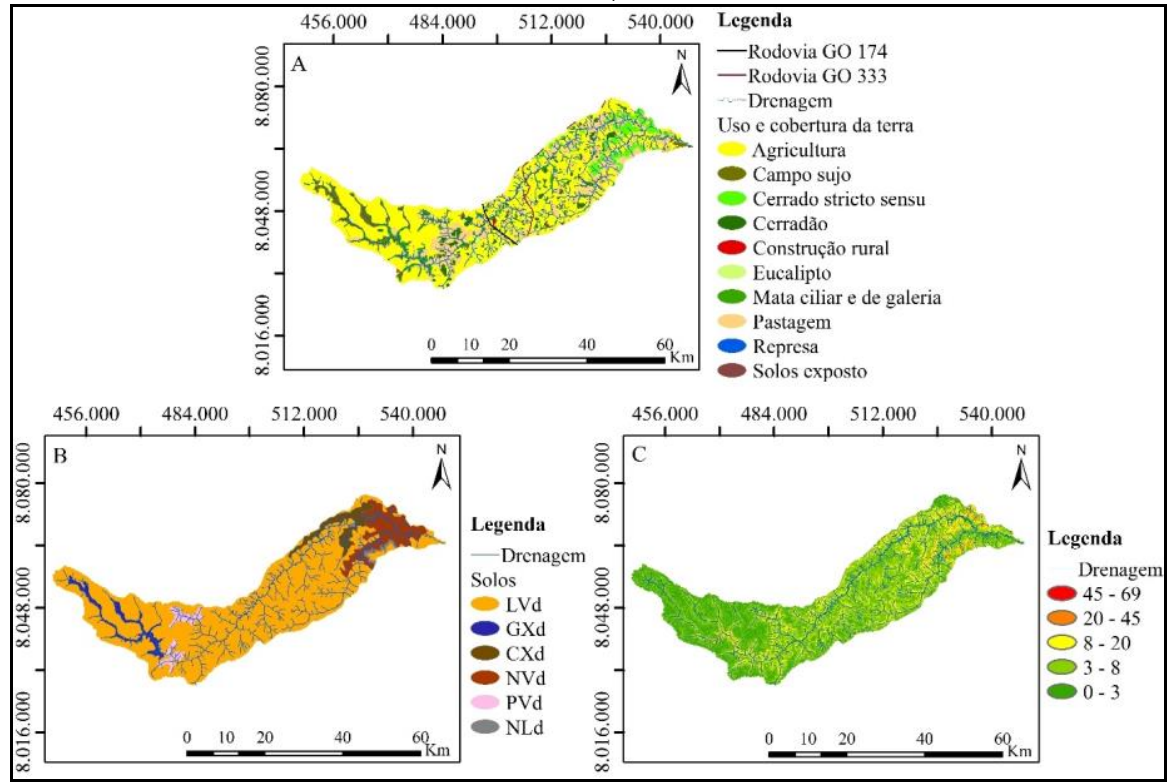

CXd: Cambissolo Háplico Distrófico; GXd: Gleissolo Háplico Distrófico; LVd: Latossolo Vermelho Distrófico; NVd: Nitossolo Vermelho Distrófico; PVd: Argissolo Vermelho Distrófico; RLd: Neossolo Litólico Distrófico. Elaborado no Sistema de Coordenadas Projetadas: Sirgas 2000, UTM e Zona 22S.

Fonte: A e C elaborado pelos autores (2019); e B pela UFV (2005)/Ruralminas (2005), (SGM - GO) (2005)/(SIC - GO, 2005), atualizado conforme Santos et al. (2013) e organizado pelos autores (2019).

Os dados climáticos (de um período de 20 anos) para entrada no modelo foram organizados em tabelas conforme manual do SWAT. A partir dos dados de insolação foram obtidos os valores de radiação por meio do modelo matemático proposto por Allen et al. (1998). Os dados estatísticos do clima da estação climatológica 83470 Rio Verde (Tabela 1) foram gerados com o uso da macro WGN Excel disponibilizada na página online do Soil e Water Assessment Tool (AGRICULTURAL..., 2019).

Tabela 1 - Sudoeste de Goiás, Cerrado Brasileiro: Dados climáticos da estação 83470 Rio Verde usados no processo de modelagem hidrológica da bacia hidrográfica do Rio Verdinho, 2019

\begin{tabular}{ccccccccccccc}
\hline Variável & Jan & Fev & Mar & Abr & Maio & Jun & Jul & Ago & Set & Out & Nov & Dez \\
\hline TMPMX & 29,3 & 30,1 & 30,16 & 29,98 & 28,45 & 28,48 & 29,12 & 31,24 & 32,8 & 32,28 & 30,39 & 29,87 \\
TMPMN & 19,66 & 19,48 & 19,38 & 18,58 & 15,68 & 14,76 & 14,35 & 15,41 & 17,94 & 19,25 & 19,34 & 19,57 \\
TMPSTDMX & 2,08 & 2,09 & 1,98 & 2,14 & 2,34 & 2,1 & 2,6 & 2,63 & 3,38 & 3,15 & 2,31 & 2,17 \\
TMPSTDMN & 0,97 & 1,11 & 1,29 & 1,99 & 2,57 & 2,32 & 2,63 & 2,85 & 2,49 & 1,89 & 1,38 & 1,19
\end{tabular}

$\begin{array}{llllll}\text { Caminhos de Geografia } & \text { Uberlândia } & \text { v. 23, n. } 85 & \text { fev./2022 } & \text { p. 261-282 } & \text { Página } 266\end{array}$




\begin{tabular}{ccccccccccccc} 
PCPMM & 219,29 & 233,89 & 301,21 & 94,26 & 35,76 & 20,46 & 8,71 & 8,7 & 42,16 & 126,15 & 235,04 & 256,26 \\
PCPSTD & 12,27 & 14,26 & 17,98 & 9,08 & 5,05 & 4,32 & 1,92 & 1,77 & 5,19 & 9,79 & 13,35 & 14,27 \\
PCPSKW & 2,92 & 3,1 & 2,87 & 4,67 & 6,53 & 10 & 8,62 & 8,05 & 6,6 & 3,93 & 2,38 & 3,18 \\
PR_W1 & 0,48 & 0,46 & 0,5 & 0,2 & 0,11 & 0,05 & 0,04 & 0,04 & 0,14 & 0,32 & 0,48 & 0,55 \\
PR_W2 & 0,79 & 0,72 & 0,67 & 0,52 & 0,32 & 0,31 & 0,23 & 0,39 & 0,4 & 0,53 & 0,66 & 0,71 \\
PCPD & 21,5 & 17,6 & 18,8 & 9,3 & 4,2 & 2,4 & 1,5 & 1,65 & 5,7 & 12,05 & 17,6 & 20,5 \\
RAINHMX & 29,05 & 45,74 & 48,61 & 32,1 & 23,67 & 22,43 & 8,86 & 7,05 & 24,59 & 30,47 & 26,15 & 47,34 \\
SOLARAV & 14,24 & 15,52 & 14,91 & 15,42 & 13,84 & 13,12 & 13,98 & 15,46 & 15,47 & 15,62 & 15,25 & 11,7 \\
DEWPT & 0,8 & 0,79 & 0,78 & 0,71 & 0,66 & 0,61 & 0,52 & 0,44 & 0,5 & 0,62 & 0,74 & 0,78 \\
WNDAV & 2,27 & 2,02 & 1,92 & 1,77 & 1,75 & 1,83 & 1,96 & 2,21 & 2,46 & 2,25 & 2,28 & 2,29 \\
RAIN_YRS & 20 & 20 & 20 & 20 & 20 & 20 & 20 & 20 & 20 & 20 & 20 & 20 \\
\hline
\end{tabular}

TMPMX: temperatura máxima média no mês $\left({ }^{\circ} \mathrm{C}\right)$; TMPMN: temperatura mínima média no mês $\left({ }^{\circ} \mathrm{C}\right)$;

TMPSTDMX: desvio padrão da temperatura máxima diária no mês $\left({ }^{\circ} \mathrm{C}\right)$; TMPSTDMN: desvio padrão da temperatura mínima diária no mês $\left({ }^{\circ} \mathrm{C}\right)$; PCPMM: precipitação mensal média $(\mathrm{mm})$; PCPSTD: desvio padrão da precipitação diária no mês (mm); PCPSKW: coeficiente de assimetria para a precipitação diária no mês; PR_W1; probabilidade de dia úmido seguido de dia seco no mês (\%); PR_W2: probabilidade de dia úmido seguido de dia úmido no mês (\%); PCPD: número médio de dias de precipitação no mês (dias); RAINHHMX: precipitação máxima de 0,5 horas $(\mathrm{mm})$; SOLARAV: radiação solar diária média no mês ( $\mathrm{MJ} \mathrm{m}^{-2} \mathrm{dia}^{-1}$ ); DEWPT: temperatura no ponto de orvalho $\left({ }^{\circ} \mathrm{C}\right)$; WNDAV: velocidade do vento diária média no mês (m s-1); e RAIN_YRS: número de anos utilizados para determinação de RAINHHMX.

Fonte: Elaborada pelo autor (2019).

Esses dados integraram o banco de dados de entrada necessário para a modelagem, sendo os mapas no formato raster, os dados tabelados sobre o uso e a cobertura da terra e os solos na extensão bdf e os dados de clima em arquivo txt.

\section{Processo de modelagem}

Na extensão ArcSWAT do ArcGIS ${ }^{\circledR}$ desenvolvida para o modelo SWAT 2012, inicialmente foi criado o projeto, vinculado ao banco de dados de entrada necessários para a modelagem (produtos cartográficos em formato raster e as tabelas em arquivo .bdf), inserido o MDE, realizada a definição de fluxo para 1400 ha e delimitada a BH do Rio Verdinho com um total de 47 sub-bacias (variando de $1.392,57$ a $7.063,20$ ha). Foram considerados 7 pontos para estimativa de vazão, estrategicamente planejados, os quais foram nomeados de Ponto 1 (P1) a Ponto 7 (P7) (Figura 3).

Figura 3 - Sudoeste de Goiás, Cerrado Brasileiro: Pontos para os quais foi realizada a estimativa de vazão na bacia hidrográfica do Rio Verdinho, 2019

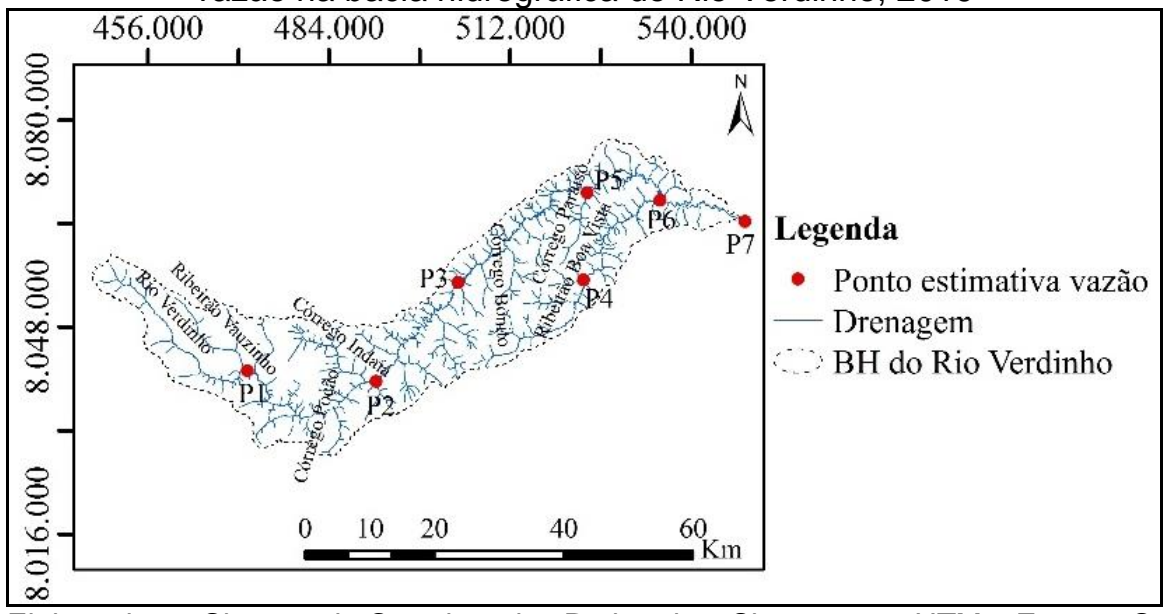

Elaborado no Sistema de Coordenadas Projetadas: Sirgas 2000, UTM e Zona 22S. Fonte: Elaborado pelos autores (2019).

O P1 fica localizado no trecho superior da bacia hidrográfica; o P2 e P3, no trecho médio, sendo que o P2 é onde se encontra, em fase de implementação, o projeto para captação de água para abastecimento público da população urbana do município de Rio Verde (GO); o P4, no trecho médio da BH do Ribeirão Boa Vista, que é o principal afluente do Rio Verdinho; o P5, no trecho baixo, onde

\begin{tabular}{|c|c|}
\hline Caminhos de Geografia & Uberlândia \\
\hline
\end{tabular}


fica localizada a estação fluviométrica (código 60785005 Fazenda Paraíso), a partir da qual foram obtidos os resultados (observados) de vazão para calibração do modelo; P6, no trecho baixo, na foz do Ribeirão Boa Vista; e P7, na foz do Rio Verdinho (Figura 3).

$\mathrm{Na}$ etapa seguinte, foram importados para o modelo e integrados os mapas de uso e cobertura da terra, de solo e da declividade, definidas as URHs sem eliminar nenhuma área dos produtos cartográficos de entrada (total de $1.421 \mathrm{URHs}$ geradas), inseridos os dados de clima de 20 anos em arquivo no formato txt. Posteriormente, foram definidas as operações de manejo por meio da edição do arquivo .mgt. Para todas as URHs cobertas por vegetação natural foi habilitada a opção de desenvolvimento inicial das plantas (Initial Plant Growth), a qual indica a ocorrência de uso da terra já em crescimento no início da simulação, e foi definido um índice de área foliar inicial de 6 (LAI_INIT = $6 \mathrm{~m}^{2} \cdot \mathrm{m}^{-2}$ ), mantendo-se constante durante todo o período de modelagem. Para as URHs cobertas com pastagem, foi feito o mesmo tratamento anterior, sendo que para o índice de área foliar inicial foi assumido um valor de 3 (LAI_INIT $=3 \mathrm{~m}^{2} \cdot \mathrm{m}^{-2}$ ). Ainda na operação de manejo, para a agricultura genérica, representou-se um sistema de sucessão de culturas com o plantio de uma cultura (soja) em $1^{\circ}$ de outubro (Plant/begin growing season), com 1.200 unidades de calor para atingir a maturação, e colheita em 15 de março (Harvest and kill); sendo para a cultura do milho safrinha, considerou-se um novo plantio em 1ำ de abril, também com 1.200 unidades de calor para maturação, com colheita definida para 15 de setembro. Em seguida, realizada a simulação mensal com aquecimento de 2 anos (1997 a 1998).

\section{Avaliação do desempenho do modelo}

Nesta etapa, para avaliar o desempenho do modelo foi gerado o ciclo hidrológico no SWAT, sendo os dados deste comparados com os de Silva e Oliveira (1999); Lima (2000) e Lima (2010) apresentados na Tabela 2. E, ainda, os resultados simulados para o P5, os dados mensais de vazão da estação 60785005 Fazenda Paraíso (com local no P5) (Figura 3), em m ${ }^{3} . \mathrm{s}^{-1}$, referentes a 15 anos (de 1999 a 2013), submetidos ao teste de Nash-Sutcliffe apresentado na Equação 3 (E3) (NASH; SUTCLIFFE, 1970) e ao coeficiente de determinação $\left(R^{2}\right)$ descrito na Equação 4 (E4). Estes modelos matemáticos foram utilizados devido se ajustarem à modelagem de vazão mensal, conforme Abbaspour (2015).

Tabela 2 - Distrito Federal (DF), Cerrado Brasileiro: Resultados do balanço hídrico anual efetuado em pequenas bacias hidrográficas não urbanizadas, 1999, 2000 e

\begin{tabular}{|c|c|c|c|c|c|c|}
\hline Referência & \multicolumn{2}{|c|}{$\begin{array}{c}\text { Silva e Oliveira } \\
(1999)\end{array}$} & \multicolumn{2}{|c|}{ Lima (2000) } & \multicolumn{2}{|c|}{ Lima (2010) } \\
\hline Ano hidrológico & \multicolumn{2}{|c|}{ 1996/1997 } & \multicolumn{2}{|c|}{ 1998/1999 } & \multicolumn{2}{|c|}{$2007 / 2008$} \\
\hline Bacia hidrográfica & \multicolumn{2}{|c|}{ Capetinga, DF } & \multicolumn{2}{|c|}{ Capetinga, DF } & \multicolumn{2}{|c|}{ Alto Jardim, DF } \\
\hline Área da bacia $\left(\mathrm{km}^{2}\right)$ & \multicolumn{2}{|c|}{10,00} & \multicolumn{2}{|c|}{10,00} & \multicolumn{2}{|c|}{104,86} \\
\hline Variável & $\mathrm{mm}_{\mathrm{ano}}{ }^{-1}$ & $\%$ & $\mathrm{~mm}_{\mathrm{ano}}^{-1}$ & $\%$ & $\mathrm{~mm}_{\mathrm{ano}}{ }^{-1}$ & $\%$ \\
\hline Precipitação & $1.744,00$ & 100,00 & $1.058,73$ & 100,00 & $1.100,00$ & 100,00 \\
\hline Escoamento superficial & 52,50 & 3,01 & 15,08 & 1,42 & 32,33 & 2,94 \\
\hline Escoamento de base & 444,00 & 25,46 & 284,39 & 26,86 & 289,89 & 26,35 \\
\hline Escoamento total & 496,50 & 28,47 & 299,47 & 28,29 & 322,22 & 29,29 \\
\hline $\begin{array}{l}\text { Variação da lâmina de água no } \\
\text { solo }\end{array}$ & * & * & $-71,77$ & $-6,78$ & * & * \\
\hline Evapotranspiração real & $1.247,50$ & 71,53 & 831,03 & 78,49 & 777,78 & 70,71 \\
\hline
\end{tabular}

Fonte: Adaptado de Silva e Oliveira (1999), Lima (2000) e Lima (2010).

$$
N S=1-\frac{\sum_{i}^{v}\left(Q_{0}-Q_{x}\right)_{i}^{2}}{\sum_{i}^{v}\left(Q_{\omega_{i}}-Q_{\pi w}\right)^{2}}
$$

Na qual: NS é uma estatística normalizada e estima a magnitude relativa da variância residual em comparação com o observado; $Q$, uma variável (neste caso, a vazão), em $\mathrm{m}^{3} \cdot \mathrm{s}^{-1} ; \mathrm{o}, \mathrm{s}$ e $\mathrm{m}$ representam observado (pela estação fluviométrica), simulado (pelo modelo) e média, respectivamente; e i, o i-ésimo medido ou dados simulados.

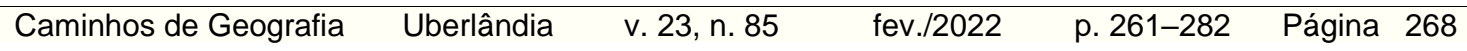




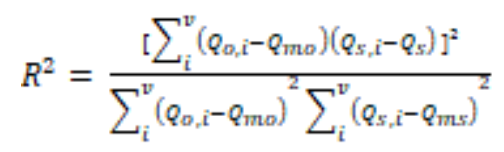

Na qual: $R^{2}$ é o coeficiente de determinação; $Q$, uma variável (neste estudo é a vazão), $\mathrm{m}^{3} . \mathrm{s}^{-1} ; \mathrm{o}, \mathrm{s}$ e $\mathrm{m}$ representam observado (pela estação fluviométrica), simulado (pelo modelo) e média, respectivamente; e i, o i-ésimo medido ou dados simulados.

O NS varia de infinito negativo a 1,00 , sendo $N S=10$ valor ideal. Um valor negativo indica que o valor médio das séries temporais observadas teria sido um melhor preditor do que o modelo (KRAUSE; BOYLE; BASE, 2005). Considerando simulações mensais, para $0,75<\mathrm{NS} \leq 1,00$, 0 modelo é muito bom; 0,65 < NS < 0,75, bom; entre 0,50 e 0,65, satisfatório; e abaixo de 0,50, inadequado. $R^{2}$ varia de 0 a 1 , com valores mais altos indicando menor variação de erro e, tipicamente, valores maiores que 0,5 são considerados aceitáveis (MORIASI et al., 2007).

Além dos testes NS e $\mathrm{R}^{2}$, para a análise dos resultados também foi considerada a estatística PBIAS, descrita na Equação 5 (E5), que mede a tendência média, em \%, dos valores simulados serem maiores ou menores do que os dados observados, sendo zero o seu valor ideal. Valores positivos e valores negativos indicam que a simulação subestimou e superestimou, respectivamente, os valores observados. Uma classificação proposta por Van Liew et al. (2003) para este coeficiente em aplicações do modelo SWAT é a seguinte: |PBIAS $\mid<10 \%$, muito bom; $10 \%<|\mathrm{PBIAS}|<15 \%$, bom; $15 \%<|\mathrm{PBIAS}|<25 \%$, satisfatório; $|\mathrm{PBIAS}|>25 \%$, insatisfatório. Também foram realizados testes de mínimo, máximo, mediana, média e desvio padrão, em planilha eletrônica, para melhor entender os resultados sem calibração do modelo. Depois de avaliado, notou-se a necessidade de calibração do modelo, sendo este processo realizado em seguida por meio do SWAT-CUP.

$P B I A=100\left[\frac{\left[\sum_{i}^{n}\left(Q_{p}-Q_{x}\right)\right.}{\Sigma_{i}^{\mathrm{M}} Q_{\infty}}\right]$

Na qual: Qo é a vazão observada (obtida pela estação fluviométrica), em $\mathrm{m}^{3} \cdot \mathrm{s}^{-1}$; Qs, a vazão simulada (pelo modelo), em $\mathrm{m}^{3} \cdot \mathrm{s}^{-1}$; e i, o i-ésimo medido ou dados simulados.

\section{Calibração do modelo}

O SWAT-CUP contém cinco procedimentos de calibração diferentes e inclui funcionalidades para validação e análise de sensibilidade. Neste estudo, foi utilizado o método Sequential Uncertainty Fitting vesion 2 (SUFI-2) (ABBASPOUR; JOHNSON; VAN GENUCHTEN, 2004; ABBASPOUR et al., 2007; ABBASPOUR, 2015) para calibração do modelo e análise de incerteza, como observado nos trabalhos de Abbaspour et al. (2015); Ferreira e Uagoda (2017); Blainski; Acosta; Nogueira (2017) e Dias et al. (2018).

No SWAT-CUP, os usuários podem ajustar manualmente as variáveis e os intervalos entre as execuções de calibração automática, sendo que a análise de sensibilidade de variável ajuda na análise de calibração e incerteza, além de ser usada para fornecer estatísticas para ajuste de qualidade. É importante ressaltar que a interação do usuário (modelador) ou componente manual da calibração SWAT-CUP exige que o modelador tenha uma melhor compreensão dos processos hidrológicos gerais e da sensibilidade da variável (ARNOLD et al., 2012; ABBASPOUR, 2015; ABBASPOUR et al., 2015).

Para calibração, foram usados os resultados, considerando dados de vazão $\left(\mathrm{m}^{3}\right.$.s $\left.{ }^{-1}\right)$ de 1999 a 2013 , simulados para o P5 (Figura 3) e observados neste mesmo ponto por meio da estação 60785005 Fazenda Paraíso. A calibração foi realizada a partir de valores paramétricos observados na literatura para ambiente no Cerrado apontados por Ferreira (2016) e Ferreira e Uagoda (2017) como sensíveis para a região, considerando as características da BH do Rio Verdinho e simulação mensal. É importante ressaltar que as variáveis usadas no processo de calibração do modelo SWAT por meio do software SWAT-CUP são, em geral, de difícil medição, sendo observado na literatura nacional e internacional que é comum realizar o ajuste do modelo a partir de variáveis quantificadas em outros estudos na região, onde fica localizada a bacia hidrográfica de interesse em modelar, assim como 
observado nos estudos de Ferreira e Uagoda (2017); Blainski; Acosta; Nogueira (2017); Dias et al. (2018) e outros.

Nesta etapa foi usado o procedimento simultâneo de calibração multisite, como observado em Leta, Griensven e Bauwensforam (2016), que pode considerar simultaneamente a variabilidade espacial da bacia e melhorar o desempenho do modelo (QI; WANG; ZHANG, 2019). Foi usado também o procedimento do algoritmo SUFI-2 no SWAT-CUP versão 2019 para realização da análise de sensibilidade, conforme observado em Abbaspour (2015); Abbaspour et al. (2015). As sensibilidades paramétricas foram determinadas usando a Equação 6 (E6).

$g=a+\sum_{i=1}^{m} \beta_{i} * b_{i}$

$\mathrm{Na}$ qual: $g$ é o valor da função objetiva; $\alpha$ e $\beta_{i}$ são coeficientes de regressão; $b_{i}$, a variável de calibração do i-ésimo valor da variável; e $m$, o número de variáveis consideradas.

O coeficiente de Nash-Sutcliffe (NS) foi usado como o valor da função objetivo e o testes $t$ de Student foi usado para identificar a significância estatística de cada variável, o valor de $p$ foi utilizado para identificar a sensibilidade relativa das variáveis e um valor de $p<0,05$ indicou variável sensível no presente estudo, conforme Abbaspour (2015).

E ainda, para obter uma parametrização quantitativa da incerteza, os valores de $P$ e $R$ foram calculados. $O$ valor $P$ representa os dados medidos agrupados pela faixa de 95 por cento de incerteza preditiva (PPU), e o valor R, expressa o comprimento relativo da banda de 95PPU em relação aos valores simulados do modelo (XUE; CHEN; WU, 2014; ABBASPOUR, 2015). O valor $P$ foi determinado pela Equação 7 (E7), e o valor de R, pela Equação 8 (E8):

$P-$ valor $=Q_{\mathrm{i}} n / N$

Na qual: Qim é o número total de pontos de dados observados entre parêntesis pela banda de 95PPU; e N, o número total de pontos de dados observados.

$R-$ valor $=\mathrm{d}_{x} / \sigma_{x}$

$\mathrm{Na}$ qual: $d_{x}$ é a distância média entre o limite superior e inferior da banda de 95PPU; $\sigma x$, o desvio padrão da simulação do modelo. $O d_{x}$ foi calculado usando a Equação 9 (E9):

$\mathrm{d}_{x}=1 / K \sum_{\mathbb{i}=1}^{k}\left(\mathrm{q}_{\mathrm{u}}-\mathrm{q}_{\mathrm{p}}\right)_{\mathrm{l}}$

Na qual: I é contador; k, o número total de pontos de dados simulados para o fluxo de q; e qu e q, o limite superior e inferior, respectivamente, da banda de 95PPU.

A incerteza de previsão de 95\% (95PPU) no SUFI-2 representa as incertezas combinadas na estrutura do modelo, variáveis e dados de entrada (ABBASPOUR, 2015). O fator $R$ pode variar entre 0 e infinito, enquanto o fator $P$ pode variar de 0 a $100 \%$ (SINGH et al., 2014). A incerteza de previsão é alta quando o valor do fator P é baixo e o fator R é alto, e vice-versa (QI; WANG; ZHANG, 2019).

Foram realizados vários testes, variando de 200 a 500 interações dentro dos intervalos utilizados na análise de sensibilidade. E para melhor entender os resultados pós processo de calibração, foram realizados testes de mínimo, máximo, mediana, média e desvio padrão, em planilha eletrônica. 


\section{Validação do modelo e análise dos resultados}

Nesta etapa foram usados os dados obtidos pela modelagem e a vazão observada referentes aos anos de 2014 a 2016. Para a validação, foram usados os intervalos das variáveis calibradas "sem quaisquer outras alterações" e executada uma iteração, considerando o mesmo número de simulações utilizado na etapa de calibragem. O processo foi executado em SUFI2, sendo realizados os ajustes necessários para o período de validação. O 95PPU e o arquivo Summary_stat (ABBASPOUR, 2015) refletiram os resultados.

Considerou-se para a análise/julgamento da validação do modelo calibrado os testes de NS (E3), $R^{2}$ (E4) e PBIAS. Moriasi et al. (2015) destacam que NS e $\mathrm{R}^{2}$ funcionam muito bem tanto para a calibração quanto para o período de validação. Abbaspour (2015) recomenda o uso dessas equações para esses processos. Depois da validação do modelo, os resultados observados e simulados de 2014 a 2016 para o P5 e os resultados de 1999 a 2016 foram analisados a partir de testes estatísticos em planilha eletrônica.

\section{RESULTADOS E DISCUSSÃO}

\section{Modelagem}

A partir do processo de modelagem da BH do Rio Verdinho para dados mensais no ArcSWAT, foram observados na análise do ciclo hidrológico, considerando os resultados sem calibração, $48,98 \%$ do volume total da precipitação pluviométrica $(1.518,4 \mathrm{~mm})$ convertido para evapotranspiração, $12,74 \%$ em escoamento superficial, $11,95 \%$ em fluxo lateral, $26,54 \%$ em água disponível para percolação, $23,38 \%$ em escoamento de base, $1,83 \%$ em ascensão capilar do aquífero raso, $1,33 \%$ para recarga do aquífero profundo e $51,02 \%$ em escoamento total. Sendo o valor do CN (curva-número) médio de 57,76 .

Ao comparar os resultados para o escoamento superficial, escoamento de base, escoamento total e evapotranspiração com os valores obtidos em estudos realizados na região Centro-Oeste do Brasil por Silva e Oliveira (1999); Lima (2000); Lima (2010), apresentados na Tabela 2, observa-se que o modelo subestimou a evapotranspiração e superestimou o escoamento superficial e, conseguinte, escoamento total.

No estudo de Ferreira e Uagoda (2017), na análise da estimativa do balanço hídrico da bacia do Ribeirão do Gama, no Distrito Federal, por meio do modelo SWAT, também é observado que a modelagem superestimou o escoamento superficial e subestimou a evapotranspiração, sendo que do volume total de precipitação pluviométrica $(1.401,2 \mathrm{~mm}), 12,16 \%$ foi convertido em escoamento superficial, e 41,09\%, em evapotranspiração.

A partir da análise dos resultados simulados e observados, testes de NS $(-3,34), R^{2}(0,81)$ e PBIAS (25), é possível afirmar que o modelo SWAT não simulou de forma satisfatória a vazão da BH do Rio Verdinho. Conforme Moriasi et al. (2007), os valores de NS < 0 são considerados como níveis não aceitáveis de desempenho. De acordo com Krause; Boyle; Base (2005), o valor médio das séries temporais observadas é um melhor preditor do que o modelo (sem calibração). O resultado para PBIAS (negativo) sugere que a simulação sem calibração superestimou os valores. $O$ valor de $P$ foi de 0,78 e de R, de 1,29, ou seja, conforme Qi; Wang; Zhang (2019), ocorreu baixa incerteza de previsão, uma vez que $P$ foi alto. Assim, foi necessário realizar o processo de calibração para obtenção de uma modelagem representativa da vazão na BH do Rio Verdinho.

Na Figura 4 é apresentada a comparação das vazões mensais simuladas e observadas, onde podese observar a tendência do modelo superestimar as vazões nas estações chuvosas e subestimar nas estações secas.

Comportamento semelhante também foi observado por Ferreira e Uagoda (2017) na análise da predição do balanço hídrico da bacia do Ribeirão do Gama (DF) e por Castro et al. (2016) no trecho superior da BH do Rio Jardim (DF).

As vazões mínima, máxima, mediana, média e o desvio padrão obtidos a partir dos dados simulados sem calibração do modelo e observados são apresentados na Tabela 3. Pode-se observar, além da discrepância, maior variabilidade para os valores simulados em relação aos observados. 
Figura 4 - Sudoeste de Goiás, Cerrado Brasileiro: Hidrograma das vazões mensais simuladas (sem calibração) e observadas, de 01/janeiro/1999 a 31/dezembro/2013, para a bacia hidrográfica do Rio Verdinho, 2019

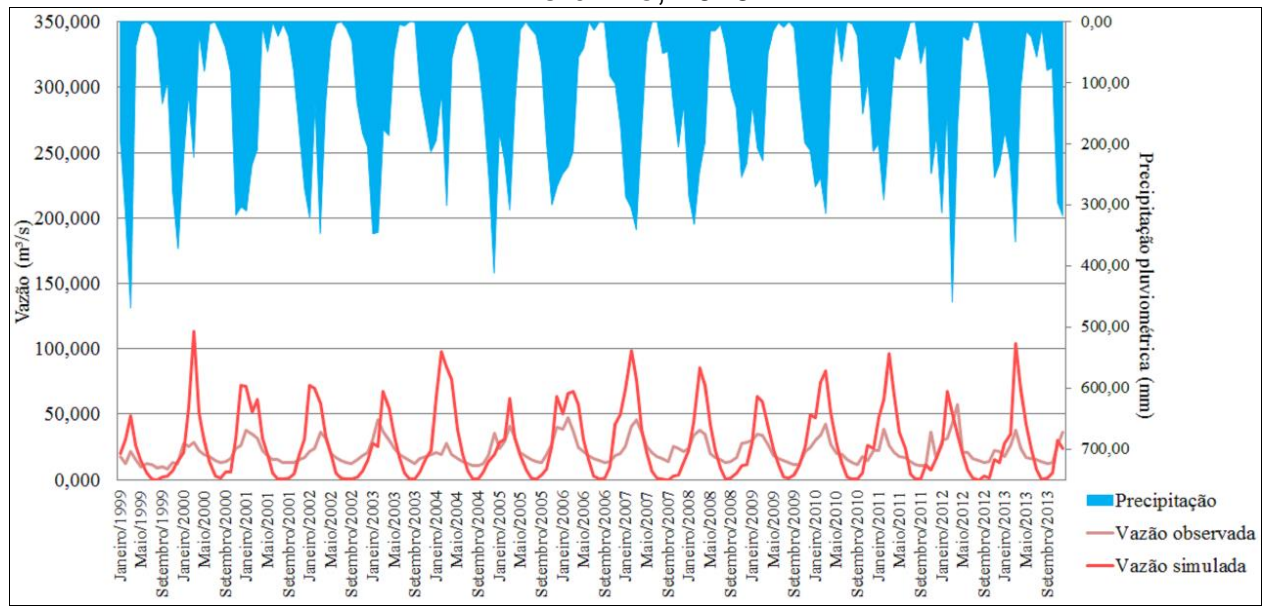

Fonte: Elaborado pelos autores (2019).

Tabela 3 - Sudoeste de Goiás, Cerrado Brasileiro: Testes estatísticos relacionados aos dados simulados (sem calibração) e observados para a bacia hidrográfica do Rio Verdinho, 2019

\begin{tabular}{ccc}
\hline \multirow{2}{*}{ Estatística } & \multicolumn{2}{c}{ Resultados $\mathrm{em} \mathrm{m}^{3} \cdot \mathrm{s}^{-1}$} \\
\cline { 2 - 3 } & Simulação sem calibração & Observados \\
\hline Mínima & 0,06 & 8,30 \\
Máxima & 113,30 & 57,70 \\
Mediana & 19,39 & 19,11 \\
Média & 26,97 & 21,63 \\
Desvio padrão & 26,89 & 9,37 \\
\hline
\end{tabular}

Fonte: Elaborada pelos autores (2019).

\section{Calibração e validação}

$\mathrm{Na}$ Tabela 4 são apresentadas as variáveis consideradas sensíveis e usadas na calibração do modelo, limites (inferior e superior) e ranking de sensibilidade para a modelagem. Observou-se que as variáveis sensíveis $(p<0,05$ e considerando a significância estatística de cada variável a partir do teste t de Student) são as apresentadas no ranking de sensibilidade de 1 a 11 , sendo as variáveis GW_DELAY (intervalo de tempo para a recarga do aquífero), CN2 (Valor do Curva Número para a condição de umidade) e SOL_K (condutividade hidráulica saturada do solo) as mais sensíveis, e REVAPMN (profundidade em aquífero raso para que aconteça o "revap"), a menos sensível (Tabela 4).

Observou-se que $50 \%$ do volume total da precipitação pluviométrica $(1.518,4 \mathrm{~mm})$ foi convertido para evapotranspiração, $1,47 \%$ em escoamento superficial, 10,8\% em fluxo lateral, 36,92\% em água disponível para percolação, $34,90 \%$ em escoamento de base, $1,96 \%$ em ascensão capilar do aquífero raso, $2,02 \%$ para recarga do aquífero profundo e $50 \%$ em escoamento total. E valor do CN médio de 35,28 , indicando menor potencial de escoamento em relação aos dados sem o processo de calibração. Foram observadas melhorias em relação aos resultados sem o processo de calibração e ao comparar com valores de referência obtidos por Silva e Oliveira (1999); Lima (2000); Lima (2010) apresentados na Tabela 2.

Ferreira e Uagoda (2017) observaram, no balanço hídrico pós calibração, que 53,54\% da precipitação pluviométrica foi convertida em evapotranspiração, 5,90\% em escoamento superficial, 9,73\% em fluxo lateral, 30,65\% em água disponível para percolação, 21,39\% em fluxo de base, 6,7\% em ascensão capilar do aquífero raso, $1,53 \%$ para a recarga do aquífero profundo e $46,45 \%$ em escoamento total. Ou seja, assim como observado no processo de modelagem e calibração para a BH do Rio Verdinho, o escoamento superficial também foi superestimado e a evapotranspiração subestimada para a BH do Ribeirão do Gama (DF).

Tabela 4 - Sudoeste de Goiás, Cerrado Brasileiro: Variáveis utilizadas na calibração do modelo

Caminhos de Geografia Uberlândia $\quad$ v. 23, n. $85 \quad$ fev./2022 $\quad$ p. 261-282 Página 272


SWAT, faixa de variação, valores ajustados e ranking sensibilidade para a bacia hidrográfica do Rio Verdinho, 2019

\begin{tabular}{|c|c|c|c|c|c|}
\hline \multirow{2}{*}{ Variável $^{1}$} & \multicolumn{2}{|c|}{ Faixa de variação² } & \multicolumn{2}{|c|}{$\begin{array}{l}\text { Valor ajustado e de } \\
\text { entrada no modelo }\end{array}$} & \multirow{2}{*}{$\begin{array}{c}\text { Ranking } \\
\text { de sensibilidade }\end{array}$} \\
\hline & $\begin{array}{l}\text { Limite } \\
\text { inferior }\end{array}$ & $\begin{array}{l}\text { Limite } \\
\text { superior }\end{array}$ & $\begin{array}{l}\text { Limite } \\
\text { inferior }\end{array}$ & $\begin{array}{l}\text { Limite } \\
\text { superior }\end{array}$ & \\
\hline GW_DELAY & 30,00 & 450,00 & 30 & 120 & 1 \\
\hline$\overline{\mathrm{C}} \mathrm{N} 2$ & $-0,30$ & 0,20 & $-0,30$ & 0,20 & 2 \\
\hline SOL_K & $-0,80$ & 0,80 & $-0,32$ & $-0,16$ & 3 \\
\hline SHALL̄ST & 2000,00 & 5000,00 & 500 & 5000 & 4 \\
\hline ESCO & 0,80 & 1,00 & 0,40 & 1,00 & 5 \\
\hline SOL_BD & $-0,60$ & $-0,40$ & $-0,60$ & $-0,40$ & 6 \\
\hline SURLAG & 0,05 & 5,00 & 0,05 & 5,00 & 7 \\
\hline RCHRG_DP & $-0,30$ & 0,30 & $-0,02$ & 0,23 & 8 \\
\hline $\mathrm{CH} N 2$ & 0,015 & 0,04 & $-0,025$ & 0,05 & 9 \\
\hline SOL AWC & $-0,05$ & 0,05 & $-0,1$ & 0,50 & 10 \\
\hline REVĀPMN & 0,00 & 500,00 & 0,00 & 500,00 & 11 \\
\hline DEEPST & 0,00 & 5000,00 & 0,00 & 5000,00 & 12 \\
\hline GWQMN & 0,00 & 2,00 & 0,00 & 1500 & 13 \\
\hline ALPHA_BF & 0,00 & 1,00 & 0,10 & 0,80 & 14 \\
\hline GWHT & 4,00 & 10,00 & 4,00 & 10,00 & 15 \\
\hline $\mathrm{CH}$ K2 & 0,00 & 2,50 & 0,00 & 2,50 & 16 \\
\hline GW REVAP & 0,00 & 0,20 & 0,02 & 0,10 & 17 \\
\hline
\end{tabular}

GW_DELAY: intervalo de tempo para a recarga do aquífero; CN2: Valor do Curva Número para a condição de umidade; SOL_K: condutividade hidráulica saturada do solo; SHALLST: quantidade de água inicial no aquífero raso; ESCO: fator de compensação da evaporação do solo; SOL BD: densidade aparente do solo; SURLAG: coeficiente de retardo do escoamento superficial; RCHRG_DP: fração da percolação da zona de raízes que recarrega o aquífero profundo e que não fará parte do balanço hídrico; $\mathrm{CH} \_\mathrm{N} 2$ : coeficiente de rugosidade de Manning; SOL_AWC: capacidade de água disponível na camada de solo; REVAPMN: profundidade em aquífero raso para que aconteça o "revap"; DEEPST: altura inicial da água no aquífero profundo; GWQMN: profundidade limite do nível de água acima do qual o fluxo de base é liberado pelo canal; ALPHA_BF: constante de recessão para o fluxo de base; GWHT: altura inicial do aquífero; $\mathrm{CH} \_\mathrm{K} 2$ : condutividade hidráulica efetiva do canal principal; e GW_REVAP: coeficiente "revap" de água subterrânea.

Fonte: Adaptado pelos autores (2019) a partir de dados de ${ }^{1,2}$ Agricultural... (2019), ${ }^{1}$ Ferreira (2016) e ${ }^{1}$ Ferreira e Uagoda (2017); e ${ }^{4}$ obtidos pelos autores.

No intuito de facilitar a comparação, os resultados do ciclo hidrológico com e sem calibração são apresentados na Tabela 5. Mesmo com a melhoria dos resultados pós calibração, somente o escoamento superficial está dentro de intervalos observados em regiões do Cerrado e os demais apresentam disparidade em relação aos dados de Silva e Oliveira (1999); Lima (2000); Lima (2010) apresentados na Tabela 2, sendo que o escoamento de base foi ligeiramente superestimado, o escoamento total superestimado e a evapotranspiração subestimada.

Tabela 5 - Sudoeste de Goiás, Cerrado Brasileiro: Dados sobre o balanço hídrico a partir do processo de modelagem no SWAT para a bacia hidrográfica do Rio Verdinho, 2019

\begin{tabular}{lcccc}
\hline \multirow{2}{*}{\multicolumn{1}{c}{ Variáveis }} & \multicolumn{2}{c}{ Modelo sem calibração } & \multicolumn{2}{c}{ Modelo calibrado } \\
\cline { 2 - 5 } & Em mm & Em \% & Em mm & Em \% \\
\hline Precipitação pluviométrica & $1.518,40$ & 100,00 & $1.518,40$ & 100,00 \\
Evapotranspiração & 743,70 & 48,98 & 759,80 & 50,04 \\
Escoamento superficial & 193,48 & 12,74 & 22,35 & 1,47 \\
Fluxo lateral & 181,51 & 11,95 & 163,64 & 10,78 \\
Percolação & 402,96 & 26,54 & 560,62 & 36,92 \\
Fluxo de base & 355,06 & 23,38 & 529,91 & 34,90 \\
Ascensão capilar do aquífero raso & 27,73 & 1,83 & 29,81 & 1,96 \\
Recarga do aquífero profundo & 20,15 & 1,33 & 30,65 & 2,02 \\
Escoamento total & 774,70 & 51,02 & 758,60 & 50,00 \\
\hline
\end{tabular}

Fonte: Elaborada pelos autores (2019)

Nota-se na Figura 5 (comparação das vazões mensais simuladas pós calibração com as vazões mensais observadas) melhor representatividade da modelagem, no entanto, é possível perceber que

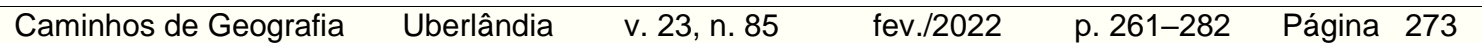


o SWAT-CUP teve dificuldade em ajustar o modelo quanto aos picos de vazão e ao fluxo de base. Contudo, ao analisar os testes de NS $(0,53)$ e $R^{2}(0,83)$, nota-se que o modelo SWAT simulou de forma satisfatória a vazão da BH do Rio Verdinho, conforme as classificações propostas por Moriasi et al. (2007).

Figura 5 - Sudoeste de Goiás, Cerrado Brasileiro (com calibração): Hidrograma das vazões simuladas e observadas para a bacia hidrográfica do Rio Verdinho, 2019

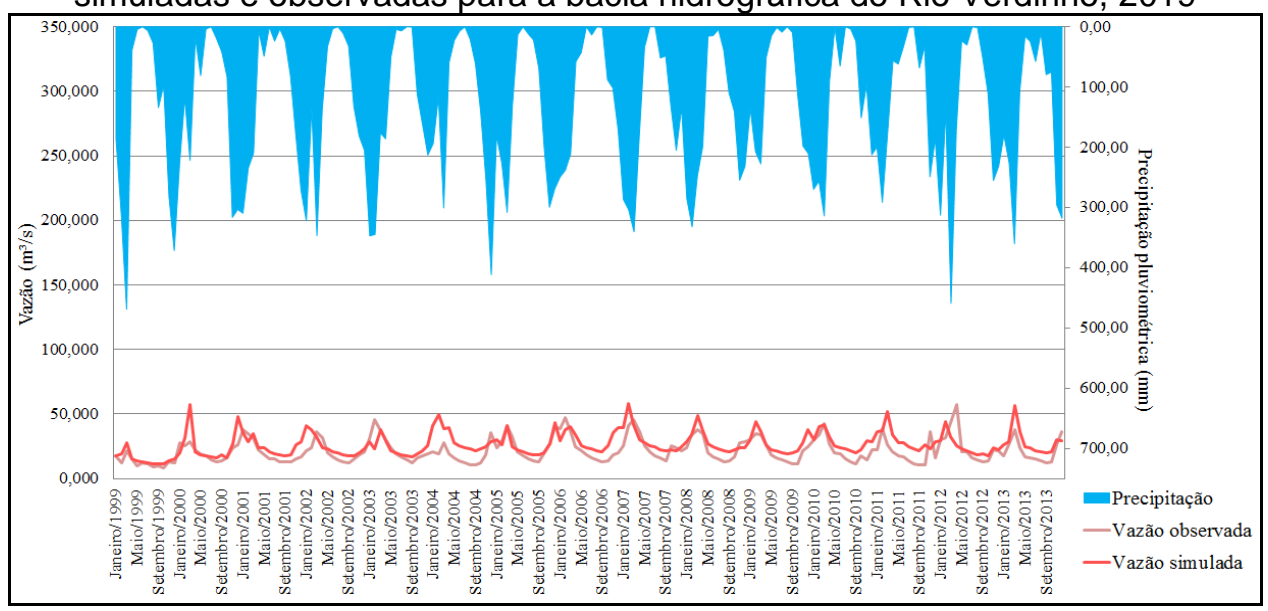

Fonte: Elaborado pelos autores (2019).

Os resultados de PBIAS $(-22,5)$ sugerem que a simulação superestimou a vazão observada, entretanto, com resultados também satisfatórios (|PBIAS| < 25), conforme Van Liew et al. (2003). Devido aos picos não ficarem bem ajustados, o teste de NS não resultou em um valor melhor (no intervalo de $0,65<\mathrm{NS}>0,75$ ou no intervalo de $0,75<\mathrm{NS} \leq 1$ ), isso porque, conforme Zhang et al. (2015), essa estatística é bastante sensível às vazões máximas. Outros dados importantes observados pós calibração do modelo são a vazão mínima $\left(11,20 \mathrm{~m}^{3} \cdot \mathrm{s}^{-1}\right)$, máxima $\left(57,81 \mathrm{~m}^{3} \cdot \mathrm{s}^{-1}\right)$, mediana $\left(24,11 \mathrm{~m}^{3} \cdot \mathrm{s}^{-1}\right)$, média $\left(26,42 \mathrm{~m}^{3} \cdot \mathrm{s}^{-1}\right)$ e desvio padrão $\left(9 \mathrm{~m}^{3} \cdot \mathrm{s}^{-1}\right)$, evidenciando melhorias substanciais em relação aos dados obtidos sem a calibração do modelo, por tanto, mais próximos dos valores observados in loco (Tabela 6).

Tabela 6 - Sudoeste de Goiás, Cerrado Brasileiro: Testes estatísticos relacionados aos dados simulados (com calibração) e observados para a bacia hidrográfica do Rio Verdinho, 2019

\begin{tabular}{ccc}
\hline \multirow{2}{*}{ Estatística } & \multicolumn{2}{c}{ Resultados em $\mathrm{m}^{3} \cdot \mathrm{s}^{-1}$} \\
\cline { 2 - 3 } & Simulação com calibração & Observados \\
\hline Mínima & 11,20 & 8,30 \\
Máxima & 57,81 & 57,70 \\
Mediana & 24,11 & 19,11 \\
Média & 26,42 & 21,63 \\
Desvio padrão & 9 & 9,37 \\
\hline
\end{tabular}
Fonte: Elaborada pelos autores (2019).

Castro et al. (2016) obtiveram, para o trecho superior da BH do Rio Jardim (Distrito Federal), NS de 0,60 , considerado satisfatório para o caso de uma modelagem com dados diários de vazão. Ferreira e Uagoda (2017) realizaram processo de calibração diária no modelo SWAT e obtiveram NS de 0,53 e $\mathrm{R}^{2}$ de 0,63 , concluindo que o modelo calibrado foi capaz de simular de forma satisfatória a vazão e o balanço hídrico da bacia do Ribeirão do Gama (Distrito Federal).

Em outro estudo sobre aplicação do modelo SWAT na avaliação do consumo de água em áreas de florestas plantadas na bacia do Rio Pará, Alto São Francisco, em Minas Gerais, realizado por Rodrigues et al. (2015), o valor obtido pós calibração para o coeficiente NS foi entre 0,757 e 0,793 para simulação diária e mensal. No estudo de Nascimento; Frede; Silva (2018), sobre modelagem da resposta do escoamento na bacia do Alto Rio do Peixe, no semiárido da Paraíba, utilizando o modelo SWAT e simulação mensal, os índices de desempenho da calibração entre os valores observados e simulados foram NS de 0,81 e $R^{2}$ de 0,82. Otsuschi; Souza; Pereira (2018), no estudo sobre

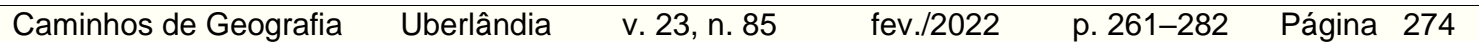


escoamento superficial e fragmentação da vegetação remanescente nas bacias dos lajeados São José e Passo dos Índios no oeste do estado de Santa Catarina, obtiveram NS de 0,82 para o desempenho do modelo a partir da calibração diária.

Silva; Henrique; Cazé (2018), na simulação das mudanças de uso e ocupação do solo e seus efeitos nas características hidrossedimentológicas em uma bacia do bioma caatinga, com relação ao desempenho do modelo SWAT na fase de calibração, os resultados para o coeficiente de NS e $\mathrm{R}^{2}$ foram 0,85 e 0,89 , respetivamente, mostrando que o modelo foi eficiente na calibração diária do escoamento superficial. Rodrigues et al. (2019), no estudo tendo como um de seus objetivos ajustar o modelo SWAT para prever a dinâmica e o equilíbrio da água no complexo de bacias hidrográficas do Parque Estadual da Serra do Rola Moça, no Quadrilátero Ferrífero, no sudeste do Brasil, obtiveram NS de 0,761 a 0,792, segundo os autores, indicando alto ajuste do modelo. Serrão et al. (2020), no estudo sobre a estimada de vazão na Bacia do Rio Tocantins-Araguaia, obtiveram desempenho excelente para o SWAT, com NS de 0,99, fatores P de 0,82 e R de 0,62.

Os melhores resultados obtidos, no processo de calibração do modelo SWAT, por Rodrigues et al. (2015); Nascimento; Frede; Silva (2018); Otsuschi; Souza; Pereira (2018); Silva; Henrique; Cazé (2018); Rodrigues et al. (2019) e Serrão et al. (2020), em relação aos observados na BH do Rio Verdinho (GO) e em outras bacias hidrográficas no Cerrado, podem ser devido aos aspectos físicos locais. Entretanto, ao contrário dos estudos realizados na BH do Rio Verdinho, na BH do Ribeirão do Gama (FERREIRA e UAGODA, 2017) e na BH do Rio Jardim (CASTRO et al., 2016), para onde o processo de calibração e validação foram consideradas as fases aquática e terrestre, Rodrigues et al. (2015), Nascimento; Frede; Silva (2018); Silva; Henrique; Cazé (2018); Rodrigues et al. (2019); Serrão et al. (2020) não avaliaram o balanço hídrico, o que pode resultar em uma modelagem inadequada.

Conforme Zhang et al. (2015), boas calibrações e validações envolvem em seus períodos: representações de anos secos e úmidos; mais de uma técnica de avaliação; e a verificação de que outras saídas do modelo (por exemplo, evapotranspiração, vazão de base) possuem resultados coerentes. Abbaspour (2015) destaca a importância do ajuste adequado da fase terrestre para melhor representatividade dos resultados. Ferreira e Uagoda (2017) destacam que a calibração dos dois processos hidrológicos (fase aquática e terrestre) são essenciais para a obtenção de resultados representativos por meio do modelo calibrado, ou seja, condizentes com os processos que ocorrem na unidade hidrográfica em análise, pois a partir da análise de ambos é possível perceber os erros e os acertos, e dessa maneira, melhor ajustar o modelo.

Na Figura 6 é apresentado o hidrograma das vazões simuladas no processo de validação do modelo e vazões observadas. Foram obtidos como resultados do processo de validação, considerando os dados dos anos de 2014 a 2016, NS de 0,50, $\mathrm{R}^{2}$ de 0,80 e PBIAS de -23,7, concluído, por tanto, que - modelo SWAT, calibrado a partir do SWAT-CUP e método SUFI-2, representa de maneira satisfatória a vazão da BH do Rio Verdinho, ficando próximo do limite não aceitável, superestimando a vazão.

Figura 6 - Sudoeste de Goiás, Cerrado Brasileiro: Hidrograma das vazões simuladas e vazões observadas (validação) para a bacia hidrográfica do Rio Verdinho, 2019

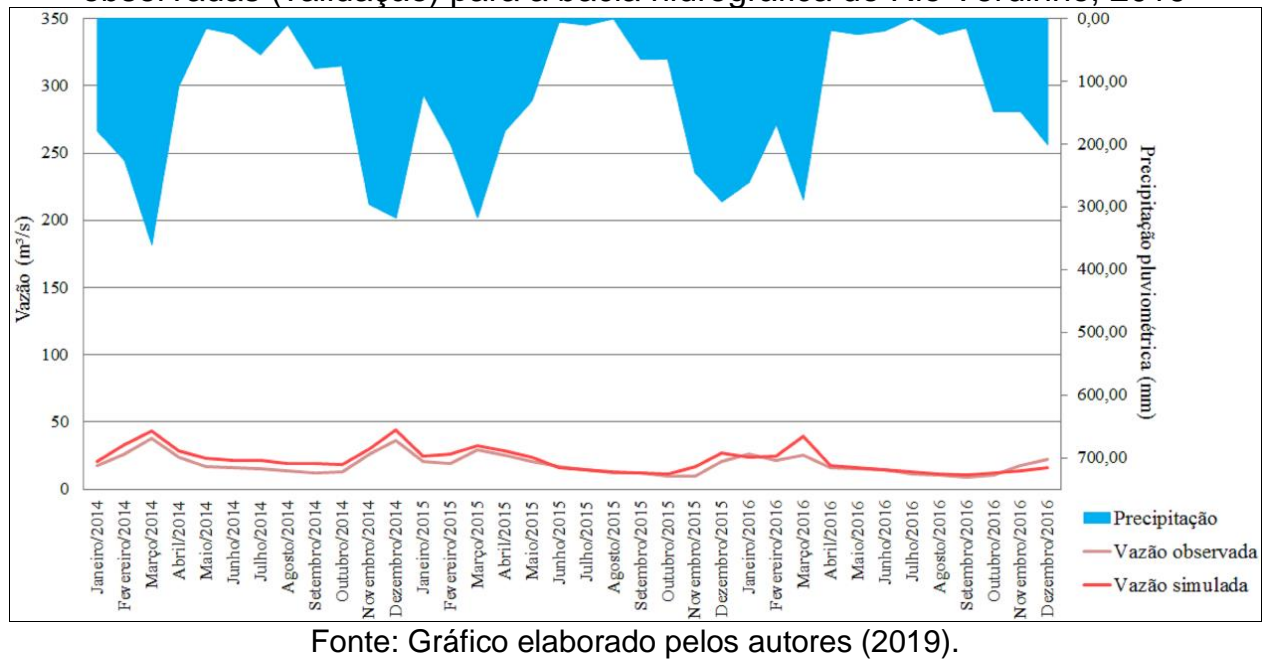


É importante ressaltar que na análise dos resultados para o período de validação, observou-se maior variabilidade para os resultados simulados em relação aos observados (Tabela 7).

Tabela 7 - Sudoeste de Goiás, Cerrado Brasileiro: Testes estatísticos relacionados aos dados simulados e observados (validação) para a bacia hidrográfica do Rio Verdinho, 2019

\begin{tabular}{ccc}
\hline \multirow{2}{*}{ Estatística } & \multicolumn{2}{c}{ Resultados em $\mathrm{m}^{3} \cdot \mathrm{s}^{-1}$} \\
\cline { 2 - 3 } & Simulação com calibração & Observados \\
\hline Mínima & 10,38 & 9,17 \\
Máxima & 44,02 & 37,89 \\
Mediana & 20,04 & 16,51 \\
Média & 21,73 & 18,51 \\
Desvio padrão & 8,92 & 7,15 \\
\hline
\end{tabular}

Fonte: Elaborada pelos autores (2019).

Na Tabela 8 e Tabela 9 são agrupados os resultados de testes estatísticos considerando os dados de 1999 a 2016, sendo na primeira, os meses com os maiores volumes (outubro a março), e na segunda, os meses com os menores volumes (abril a setembro) de precipitação pluviométrica na região.

Tabela 8 - Sudoeste de Goiás, Cerrado Brasileiro: Estatística descritiva para as vazões simuladas (com calibração) e observadas nos sete pontos na bacia hidrográfica do Rio Verdinho, considerando a série histórica e os meses com maior volume de precipitação pluviométrica, 1999 a 2016

\begin{tabular}{|c|c|c|c|c|c|c|c|c|c|}
\hline \multirow{2}{*}{ Mês } & \multirow{2}{*}{ Estatística } & \multicolumn{8}{|c|}{ Resultados em m $\mathrm{m}^{3} \cdot \mathrm{s}^{-1}$} \\
\hline & & P1S & P2S & P3S & P4S & P5S & P5O & P6S & P7S \\
\hline \multirow[t]{5}{*}{ Out. } & Méd. & 3,76 & 11,20 & 16,18 & 2,64 & 20,32 & 14,27 & 4,65 & 27,34 \\
\hline & Med. & 3,89 & 11,40 & 16,18 & 2,67 & 20,81 & 13,37 & 4,75 & 28,41 \\
\hline & Máx. & 4,62 & 14,14 & 20,93 & 3,59 & 26,45 & 25,38 & 6,38 & 35,69 \\
\hline & Mín. & 2,10 & 6,33 & 9,21 & 1,53 & 11,63 & 8,29 & 2,63 & 15,54 \\
\hline & DP & 0,62 & 1,85 & 2,74 & 0,48 & 3,45 & 4,04 & 0,90 & 4,74 \\
\hline \multirow[t]{5}{*}{ Nov. } & Méd. & 4,17 & 12,99 & 19,48 & 3,58 & 25,28 & 20,96 & 6,22 & 34,41 \\
\hline & Med. & 4,17 & 13,13 & 19,75 & 3,53 & 25,46 & 20,09 & 6,28 & 34,25 \\
\hline & Máx. & 5,72 & 17,92 & 27,05 & 5,12 & 35,32 & 36,27 & 8,90 & 48,30 \\
\hline & Mín. & 2,32 & 7,38 & 11,16 & 1,87 & 13,62 & 10,14 & 3,02 & 18,18 \\
\hline & DP & 0,70 & 2,22 & 3,49 & 0,79 & 4,71 & 6,35 & 1,44 & 6,64 \\
\hline \multirow[t]{5}{*}{ Dez. } & Méd. & 4,92 & 15,64 & 23,70 & 4,49 & 30,79 & 24,56 & 7,64 & 41,82 \\
\hline & Med. & 4,42 & 13,84 & 20,64 & 4,13 & 28,38 & 21,94 & 7,31 & 39,59 \\
\hline & Máx. & 7,73 & 25,37 & 41,20 & 7,17 & 48,04 & 40,29 & 11,55 & 61,35 \\
\hline & Mín. & 2,36 & 7,78 & 12,08 & 2,28 & 15,52 & 12,30 & 3,75 & 20,87 \\
\hline & $\mathrm{DP}$ & 1,39 & 4,58 & 7,30 & 1,37 & 8,75 & 7,84 & 2,23 & 11,52 \\
\hline \multirow[t]{5}{*}{ Jan. } & Méd. & 4,84 & 15,10 & 22,60 & 4,39 & 30,11 & 25,80 & 7,74 & 41,49 \\
\hline & Med. & 4,87 & 15,13 & 22,58 & 4,24 & 29,32 & 25,02 & 7,50 & 40,49 \\
\hline & Máx. & 6,55 & 20,45 & 30,76 & 6,43 & 41,29 & 38,91 & 12,13 & 58,20 \\
\hline & Mín. & 2,97 & 9,57 & 14,38 & 2,44 & 17,58 & 17,78 & 3,89 & 23,40 \\
\hline & DP & 1,05 & 3,41 & 5,32 & 1,11 & 6,89 & 6,37 & 2,10 & 9,63 \\
\hline \multirow[t]{5}{*}{ Fev. } & Méd. & 5,67 & 18,01 & 27,19 & 5,25 & 35,74 & 30,26 & 9,08 & 48,95 \\
\hline & Med. & 5,67 & 17,67 & 26,58 & 5,37 & 35,21 & 30,38 & 9,44 & 49,58 \\
\hline & Máx. & 9,02 & 31,65 & 49,99 & 8,20 & 57,81 & 47,28 & 14,13 & 74,68 \\
\hline & Mín. & 3,09 & 9,93 & 15,32 & 2,75 & 18,96 & 11,84 & 4,35 & 25,25 \\
\hline & DP & 1,36 & 4,81 & 7,83 & 1,52 & 9,42 & 9,55 & 2,67 & 12,83 \\
\hline \multirow{5}{*}{ Mar. } & Méd. & 6,48 & 21,02 & 32,14 & 6,21 & 41,90 & 34,62 & 10,52 & 57,09 \\
\hline & Med. & 6,76 & 20,52 & 31,04 & 5,91 & 41,17 & 36,77 & 10,47 & 56,29 \\
\hline & Máx. & 7,88 & 26,91 & 44,48 & 9,33 & 57,68 & 45,96 & 14,89 & 78,63 \\
\hline & Mín. & 4,05 & 14,25 & 22,80 & 4,20 & 27,77 & 21,24 & 6,36 & 36,56 \\
\hline & DP & 1,03 & 3,68 & 6,30 & 1,46 & 8,28 & 6,98 & 2,51 & 11,57 \\
\hline
\end{tabular}

Méd.: média; Med.: mediana; Máx.: máxima; Mín.: mínima; e DP: desvio padrão.

P1: Ponto 1; P2: Ponto 2; P3: Ponto 3; P4: Ponto 4; P5: Ponto 5; P6: Ponto 6; P7: Ponto 7; O: observada; S: simulada.

Fonte: Elaborada pelos autores (2019).

$\begin{array}{lllll}\text { Caminhos de Geografia } \quad \text { Uberlândia } & \text { v. 23, n. } 85 & \text { fev./2022 } & \text { p. 261-282 } & \text { Página } 276\end{array}$


Tabela 9 - Sudoeste de Goiás, Cerrado Brasileiro: Estatística descritiva para as vazões simuladas (com calibração) e observadas nos sete pontos na bacia hidrográfica do Rio Verdinho, considerando a série histórica e os meses com menor volume de precipitação pluviométrica, 1999 a 2016

\begin{tabular}{|c|c|c|c|c|c|c|c|c|c|}
\hline \multirow{2}{*}{ Mês } & \multirow{2}{*}{ Estatística } & \multicolumn{8}{|c|}{ Resultados em m³. $\mathrm{s}^{-1}$} \\
\hline & & P1S & P2S & P3S & P4S & P5S & P5O & P6S & P7S \\
\hline \multirow[t]{5}{*}{ Abr. } & Méd. & 5,37 & 16,12 & 23,29 & 3,84 & 29,30 & 27,26 & 6,79 & 39,59 \\
\hline & Med. & 5,56 & 15,77 & 22,36 & 3,71 & 28,91 & 25,14 & 6,65 & 39,48 \\
\hline & Máx. & 6,86 & 21,67 & 33,09 & 5,48 & 39,78 & 57,68 & 10,14 & 52,44 \\
\hline & Mín. & 2,90 & 8,73 & 12,59 & 1,91 & 15,26 & 15,58 & 3,22 & 20,21 \\
\hline & DP & 0,99 & 3,28 & 5,18 & 1,02 & 6,51 & 9,56 & 1,80 & 8,89 \\
\hline \multirow[t]{5}{*}{ Maio } & Méd. & 4,75 & 13,82 & 19,57 & 3,01 & 24,34 & 18,95 & 5,44 & 32,79 \\
\hline & Med. & 4,73 & 13,64 & 19,68 & 3,03 & 24,15 & 19,43 & 5,49 & 33,38 \\
\hline & Máx. & 5,70 & 17,01 & 24,63 & 4,69 & 33,53 & 25,15 & 8,83 & 46,66 \\
\hline & Mín. & 2,72 & 8,12 & 11,67 & 1,71 & 13,94 & 10,15 & 2,84 & 18,33 \\
\hline & DP & 0,75 & 2,17 & 3,11 & 0,60 & 4,17 & 3,38 & 1,21 & 5,86 \\
\hline \multirow[t]{5}{*}{ Jun. } & Méd. & 4,45 & 12,89 & 18,18 & 2,74 & 22,46 & 16,94 & 4,95 & 30,17 \\
\hline & Med. & 4,49 & 12,96 & 18,26 & 2,85 & 22,94 & 16,90 & 5,12 & 31,49 \\
\hline & Máx. & 5,34 & 15,29 & 21,59 & 3,47 & 27,62 & 20,56 & 6,54 & 37,76 \\
\hline & Mín. & 2,53 & 7,50 & 10,72 & 1,54 & 12,75 & 12,26 & 2,57 & 16,72 \\
\hline & DP & 0,71 & 1,99 & 2,80 & 0,45 & 3,54 & 2,23 & 0,93 & 4,90 \\
\hline \multirow[t]{5}{*}{ Jul. } & Méd. & 4,18 & 12,11 & 17,07 & 2,57 & 21,06 & 14,81 & 4,64 & 28,28 \\
\hline & Med. & 4,21 & 12,02 & 16,84 & 2,75 & 21,90 & 15,12 & 4,76 & 30,09 \\
\hline & Máx. & 4,88 & 14,38 & 20,52 & 3,02 & 24,48 & 17,73 & 5,69 & 33,20 \\
\hline & Mín. & 2,39 & 7,09 & 10,15 & 1,46 & 12,05 & 11,23 & 2,42 & 15,79 \\
\hline & DP & 0,66 & 1,84 & 2,56 & 0,41 & 3,22 & 1,73 & 0,86 & 4,47 \\
\hline \multirow[t]{5}{*}{ Ago. } & Méd. & 3,93 & 11,37 & 16,00 & 2,42 & 19,76 & 12,88 & 4,36 & 26,51 \\
\hline & Med. & 3,96 & 11,34 & 15,89 & 2,54 & 19,99 & 13,24 & 4,45 & 27,79 \\
\hline & Máx. & 4,59 & 13,41 & 19,07 & 2,82 & 22,93 & 15,75 & 5,34 & 31,23 \\
\hline & Mín. & 2,24 & 6,62 & 9,45 & 1,36 & 11,20 & 8,81 & 2,26 & 14,63 \\
\hline & DP & 0,61 & 1,72 & 2,40 & 0,37 & 2,98 & 1,65 & 0,77 & 4,10 \\
\hline \multirow[t]{5}{*}{ Set. } & Méd. & 3,78 & 11,00 & 15,58 & 2,42 & 19,40 & 11,98 & 4,35 & 26,08 \\
\hline & Med. & 3,85 & 11,06 & 15,85 & 2,51 & 20,09 & 12,12 & 4,40 & 27,25 \\
\hline & Máx. & 4,38 & 12,72 & 17,98 & 2,80 & 22,41 & 13,96 & 5,16 & 30,24 \\
\hline & Mín. & 2,27 & 6,74 & 9,65 & 1,43 & 11,56 & 9,27 & 2,36 & 15,17 \\
\hline & DP & 0,54 & 1,46 & 1,99 & 0,31 & 2,47 & 1,36 & 0,69 & 3,44 \\
\hline
\end{tabular}

Méd.: média; Med.: mediana; Máx.: máxima; Mín.: mínima; e DP: desvio padrão.

P1: Ponto 1; P2: Ponto 2; P3: Ponto 3; P4: Ponto 4; P5: Ponto 5; P6: Ponto 6; P7: Ponto 7; O: observada; S: simulada.

Fonte: Elaborada pelos autores (2019).

Cumpre dar ênfase no P2, onde está sendo implementado um projeto de captação de água para abastecimento da população urbana rio-verdense. Neste ponto o menor valor de vazão foi de 6,33 $\mathrm{m}^{3} \cdot \mathrm{s}^{-1} \mathrm{em}$ outubro, o valor máximo de $31,656,33 \mathrm{~m}^{3} \cdot \mathrm{s}^{-1}$ e maior vazão média de $21,02 \mathrm{~m}^{3} \cdot \mathrm{s}^{-1}$, ambos em março. Para o P7, ou seja, considerando toda a vazão hídrica da unidade hidrográfica de estudo, são observados valor mínimo de 14,63 $\mathrm{m}^{3} \cdot \mathrm{s}^{-1}$ (agosto), valor máximo de $78,63 \mathrm{~m}^{3} \cdot \mathrm{s}^{-1}$ e maior vazão média de $57,09 \mathrm{~m}^{3} \cdot \mathrm{s}^{-1}$ (março). Nota-se que as vazões aumentaram de outubro a março e diminuíram de abril a setembro, condizentes com o comportamento pluviométrico na área de estudo (Tabela $8 \mathrm{e}$ Tabela 9).

A dificuldade do SWAT-CUP em ajustar os picos de vazão e o fluxo de base em ambientes no Cerrado tem relação com a evapotranspiração subestimada no processo de modelagem pelo SWAT e, conseguinte, alto volume de água no sistema. Essa subestimativa é devido na composição matemática desse preditor constar o período de dormência da vegetação, no qual o índice de área foliar é reduzido para o valor mínimo permitido, dado pela variável ALAI_MIN, o qual, por padrão, é de $0,75 \mathrm{~m}^{2} \cdot \mathrm{m}^{-2}$ para mata e 0 para os demais usos, o que não é condizente com o ciclo de desenvolvimento de vegetação em regiões de clima tropical e subtropical. O estado de dormência das plantas, associado ao fotoperíodo com conseguinte queda das folhas, foi programado no modelo SWAT por ter sido desenvolvido inicialmente para regiões frias, onde as plantas entram em dormência em determinado período do ano, o que não ocorre em regiões de clima tropical e subtropical, como no Cerrado. 
Portanto, é necessário desativar o período de dormência da vegetação, modificando a sub-rotina no arquivo dormant.f, para que o processo de modelagem e calibração simule a vazão na BH do Rio Verdinho com o melhor desempenho possível do modelo SWAT, ou seja, de muito bom a ótimo. Entretanto, não é possível fazer esse ajuste diretamente na interface do ArcSWAT, sendo necessário entender a linguagem de programação Fortran, uma vez que o código fonte desse modelo é baseado nessa linguagem, o que torna difícil para o modelador sem conhecimento dessa linguagem de programação alcançar o melhor desempenho possível no processo de modelagem por essa ferramenta em ambientes no Cerrado. Depois da modificação do modelo, são necessários estudos no intuito de verificar como outros componentes simulados, por exemplo, produção de sedimentos, agroquímicos (pesticidas, fertilizantes etc.) e qualidade hídrica (variáveis físicas, químicas e microbiológicas), comportam-se em relação à referida modificação.

\section{CONSIDERAÇÕES FINAIS}

O modelo SWAT sem a calibração, por meio do SWAT-CUP, superestimou as vazões nos períodos chuvosos e subestimou na época de estiagem, não simulando de forma adequada a fase terrestre (evapotranspiração, escoamento superficial e fluxo de base) na BH do Rio Verdinho, Sudoeste de Goiás, Cerrado Brasileiro. A partir dos resultados, fica evidente que o modelo SWAT, pós processo de calibração, simulou de forma satisfatória a vazão na unidade hidrográfica analisada.

Mesmo obtendo melhores resultados pós calibração do modelo, observou-se que o SWAT-CUP teve dificuldade de ajustar as variáveis terrestres evapotranspiração e escoamento de base. Essa dificuldade tem relação com a evapotranspiração subestimada pelo SWAT, resultando em maior volume hídrico no sistema e, conseguinte, simulação não tão representativa para as fases terrestre e aquática, ou seja, não resultando no melhor desempenho possível de se obter com modelo em questão.

A subestimação da evapotranspiração tem relação com o período de dormência da vegetação, que compõe o código fonte do modelo SWAT, por meio da sub-rotina no arquivo dormant.f, devido ao referido modelo ter sido desenvolvido para ambientes de áreas temperadas, ou seja, para ambientes com condições climáticas diferentes dos ambientes de Cerrado, onde a vegetação não entra em estado de dormência na época fria do ano ou período de neve. Assim, para estudos futuros na BH do Rio Verdinho, no intuito de melhor estimar a evapotranspiração, facilitar o processo de modelagem e, conseguinte, melhorar a representatividade dos resultados, recomenda-se desativar o período de dormência da vegetação, modificando a sub-rotina no arquivo dormant.f para que o processo de modelagem e calibração simule a vazão com o melhor desempenho possível do modelo SWAT. Recomenda-se, ainda, estudos adicionais tendo em vista analisar como outros componentes simulados pelo modelo (por exemplo, produção de sedimentos, agroquímicos e qualidade hídrica) foram representados a partir dessa alteração.

Esses resultados servirão de base para outros estudos em ambientes de clima tropical, sobretudo de Cerrado e mais especificamente para a região Sudoeste de Goiás, sendo que para esta não foram observados estudos com o uso do modelo SWAT. Os resultados também subsidiarão ações e políticas públicas efetivas e eficientes de planejamento e gestão hídrica da BH do Rio Verdinho (uso e cobertura da terra, práticas e manejo conservacionistas, enquadramento de corpos hídricos, qualidade hídrica e outros). É importante ressaltar que novos estudos estão sendo realizados no intuito de ajustar o modelo SWAT para a BH do Rio Verdinho, obter resultados mais representativos, inclusive para calibração diária, e disponibilizar dados para subsidiar o uso desse modelo na região Sudoeste de Goiás.

\section{REFERÊNCIAS}

ABBASPOUR, K. C.; JOHNSON, C. A.; VAN GENUCHTEN, M. TH. Estimating uncertain flow and transport parameters using a sequential uncertainty fitting procedure. Vadose Zone Journal, v. 3 n. 4, p. 1340-1352, nov. 2004. https://doi.org/10.2113/3.4.1340

ABBASPOUR, K. C.; YANG, J. ; MAXIMOV, I. ; SIBER, R. ; BOGNER, K. ; MIELEITINER, J. ; ZOBRIST, J. ; SRINIVASAN, R. Modelling hydrology and water quality in the pre-alpine/alpine Thur watershed using SWAT. Journal of Hydrology, v. 333 n. 4, p. 413-430, fev. 2007.

https://doi.org/10.1016/i.jhydrol.2006.09.014

$\begin{array}{lllll}\text { Caminhos de Geografia } \quad \text { Uberlândia } & \text { v. 23, n. } 85 \quad \text { fev./2022 } & \text { p. 261-282 } & \text { Página } 278\end{array}$


ABBASPOUR, K. C. E. ROUHOLAHNEJADA, E.; VAGHEFIA, S.; SRINIVASANB, R.; YANGAC, H.; KLØVEDET, B. A continental-scale hydrology and water quality model for Europe: Calibration and uncertainty of a high-resolution large-scale SWAT model. Journal of Hydrology, v. 524, p. 733-752, may 2015. https://doi.org/10.1016/i.jhydrol.2015.03.027

ABBASPOUR, K. C. SWAT Calibration and Uncertainty Programs. 2015. Disponível em: https://swat.tamu.edu/media/114860/usermanual swatcup.pdf. Acesso em: 20 abr. 2019.

AGÊNCIA NACIONAL DE ÁGUAS - ANA. Plano de recursos hídricos e enquadramento dos corpos hídricos superficiais da bacia hidrográfica do rio Paranaíba, 2013, Brasília. Disponível em:

http://arquivos.ana.gov.br/institucional/sge/CEDOC/Catalogo/2013/planoRecursosHidricosParanaibaR esumo.pdf. Acesso em 20 set. 2019.

HidroWeb. Série histórica de precipitação. Disponível em:

<http://www.snirh.gov.br/hidroweb/publico/apresentacao.jsf>. Acesso em: 25 fev. 2018.

AGRICULTURAL RESEARCH SERVICE; TEXAS A \& M UNIVERSITY. Calculate statistics needed to create weather station files. WGN Excel macro. Disponível em: https://swat.tamu.edu/software/. Acesso em 20 out. 2018.

ALLEN, R. G.; PEREIRA, L. S.; RAES, D.; SMITH, M. Crop evapotranspiration: Guidelines forcomputing crop water requirements. Rome: FAO, 1998. 300 p. (FAO - Irrigation and Drainage Paper, 56). Disponível em: http://www.fao.org/3/X0490E/X0490E00.htm. Acesso em: 4 jun. 2019.

ALMEIDA, A. C.; SOARES, J. V. Comparação entre uso de água em plantações de Eucalyptus grandis e floresta ombrófila densa (Mata Attântica) na costa leste do Brasil. Revista Árvore, v. 27, n. 2, p. 159-170, 2003. http://dx.doi.org/10.1590/S0100-67622003000200006

AMAZON S3. Imagem Raster. Disponível em: http://sentinel-pds.s3-website.eu-central1.amazonaws.com/. Acesso em: 27 maio 2018.

ARNOLD, J. G. ; SRINIVASAN, R. ; MUTTIAH, R. S. ; WILLIAMS, J. R. Large area hydrologic modeling and assessment. Part I: Model development. Journal of the American Water Resources Association, v. 34, n. 1, p. 73-89, feb. 1998. https://doi.org/10.1111/i.1752-1688.1998.tb05961.x

ARNOLD, J. G.; MORIASI, D. N.; GASSMAN, P. W.; ABBASPOUR, K. C.; WHITE, M. J.; SRINIVASAN, R.; SANTHI, C.; HARMEL, R. D.; VAN GRIENSVEN, A.; VAN LIEW, M. W.; KANNAN, N.; JHA, M. K. SWAT: Model Use, Calibration, and Validation. Transactions of the ASABE, v. 55, n. 4, p. 1491-1508, 2012. https://doi.org/10.13031/2013.42256

ARROIO JUNIOR, P. P. Aprimoramento das rotinas e parâmetros dos processos hidrológicos do modelo computacional Soil and Water Assessment Tool - SWAT. Tese (Doutorado em Ciências da Engenharia Ambiental) - São Carlos: Universidade de São Paulo. 2016.

AWOTWI, A.; ANORNUB, G. K.; QUAYE-BALLARD, J. A.; ANNORD, T.; FORKUO, E. K.; HARRIS, E,. AGYEKUM, J. TERLABIE, J. L. Water balance responses to land-use/land-cover changes in the Pra River Basin of Ghana, 1986-2025. Catena, v. 182, p. 1-13, 2019.

https://doi.org/10.1016/i.catena.2019.104129

BALDISSERA, G. C. Aplicabilidade do modelo de simulação hidrológica SWAT (Soil andWater Assessment Tool) para a bacia hidrográfica do rio Cuiabá/MT. Dissertação (Mestrado em Física e Meio Ambiente) - Cuiabá: Universidade Federal do Mato Grosso. 2005

BANCO DE DADOS METEOROLÓGICOS PARA ENSINO E PESQUISA - BDMEP. Dados de precipitação de janeiro de 1996 a dezembro de 2016. Disponível em: http://www.inmet.gov.br/projetos/rede/pesquisa/. Acesso em: 08 fev. 2019.

BLAINSKI, E.; ACOSTA, E.; NOGUEIRA, P. C. P. Calibração e validação do modelo SWAT para simulação hidrológica em uma bacia hidrográfica do litoral norte catarinense. Revista Ambiente \& Água, v. 12, n. 2, p. 226-237, mar./apr. 2017. https://doi.org/10.4136/1980-993X

CASTRO, B. K.; ROIG, H. L.; LIMA, J. E. F. W.; FERRIGO, S. Aplicação de série temporal mínima para simulação de vazões em bacia experimental do cerrado. Revista Brasileira de Cartografia, v. 68 , n. 8, p. 1497-1513, set./out. 2016.

http://www.seer.ufu.br/index.php/revistabrasileiracartografia/article/view/44375 
COHEN, J. Um coeficiente de concordância para escalas nominais. Educ. Psychol. Meas., v. 20, p. 37 - 46, 1960. https://doi.org/10.1177/001316446002000104

DIAS, V. S.; LUZ, M. P.; MEDERO, G. M.; NASCIMENTO, D. T. F.; OLIVEIRA, W. N.; MERELLES, L. R. O. Historical Streamflow Series Analysis Applied to Furnas HPP Reservoir Watershed Using the SWAT Model. Water, v. 10, n. 4, p. 1-13, april 2018. https://doi.org/10.3390/w10040458

SANTOS, H. G. dos; JACOMINE, P. K. T.; ANJOS, L. H. C. dos; OLIVEIRA, V. A. de; LUMBRERAS, J. F.; COELHO, M. R.; ALMEIDA, J. A. de; ARAUJO FILHO, J. C. de; OLIVEIRA, J. B. de; CUNHA, T. J. F. Sistema brasileiro de classificação de solos. Brasília, DF: Embrapa, 2013.

ESRI. ArcGIS Desktop: Release 10.6. ${ }^{\circledR}$. 2019. Redlands, CA: Environmental Systems Research Institute.

EUROPEAN SPACE AGENCY - ESA. MultiSpectral Instrument (MSI) Overview. Disponível em: https://earth.esa.int/web/sentinel/technical-guides/sentinel-2-msi/msi-instrument. Acesso em: 25 fev. 2019.

FERREIRA, L. G.; URBAN, T. J.; NASCIMENTO, A.; ARAÚJO, F. M. Use of Orbital LIDAR in the Brazilian Cerrado Biome: Potential Applications and Data Availability. Remote Sensing, v. 3, n. 10, p. 2187-2206, 2011. https://doi.org/10.3390/rs3102187

FERREIRA, R. S. Análise da produção de carga líquida e sólida na bacia do ribeirão do Gama- DF através do modelo SWAT. Dissertação (Mestrado em Geografia) - Brasília: Universidade de Brasília. 2016.

FERREIRA, R. S.; UAGODA, R. E. Análise da predição do balanço hídrico da bacia do Ribeirão do Gama-DF através do modelo SWAT. Revista Brasileira de Geografia Física, v. 10, n. 3, p. 880-893, 2017. https://doi.org/10.5935/1984-2295.20170057

FIGUEIREDO, G. C.; VIEIRA, C. A. O. Estudo do comportamento dos índices de Exatidão Global, Kappa e Tau, comumente usados para avaliar a classificação de imagens do sensoriamento remoto. In: XIIV Simpósio Brasileiro de Sensoriamento Remoto, 2007, Florianópolis, SC. Anais do XIIV Simpósio Brasileiro de Sensoriamento Remoto. Inpe, Florianópolis, SC: 2007.

FUNDAÇÃO RURAL MINAS - RURALMINAS. Mapa de Solos do Plano Diretor da Bacia do Rio Paranaíba, na escala 1:250.000, geração 01 de março de 2005.

GOOGLE. Google Earth. Versão 2017. 2017. Imagem de áreas localizadas na bacia hidrográfica do Ribeirão das Abóboras, em Rio Verde (GO). Disponível em: https://www.google.com/int//ptBR/earth/desktop/. Acesso em: 28 de nov. 2018.

INSTITUTO BRASILEIRO DE GEOGRAFIA E ESTATÍSTICA - IBGE. Brasil. População 2019 (estimativa). 2019. Disponível em: https://cidades.ibge.gov.br/brasil/go/rio-verde/panorama. Acesso em: 15 dez. 2019.

INSTITUTO NACIONAL DE PESQUISA ESPACIAL - INPE. Topodata/Modelo Digital de Elevação (MDE). Disponível em: http://www.dsr.inpe.br/topodata/. Acesso em 20 nov. 2018.

KRAUSE, P.; BOYLE, D.P.; BÄSE, F. Comparison of different efficiency criteria for hydrological model assessment. Advances in Geosciênces, v. 5, p. 89-97, dec. 2005. https://doi.org/10.5194/adgeo-589-2005

KRYSANOVA, V.; WHITE, M. Advances in water resources assessment with SWAT-an overview. Hydrological Sciences Journal, v. 60, n. 5, p. 770-783, april. 2015.

https://doi.org/10.1080/02626667.2015.1029482

LANDIS, J. R.; KOCH, G. G. The measurement of observer agreement for categorical data. Biometrics, v.33, n.1, p.159-174, 1977. https://doi.org/10.2307/2529310

LETA, O. T.; VAN GRIENSVEN, A.; BAUWENS, W. Effect of single and multisite calibration techniques on the parameter estimation, performance, and output of a SWAT model of a spatially heterogeneous catchment. Journal of Hydrologic Engineering. v. 22, set. 2016. https://doi.org/10.1061/(ASCE)HE.1943-5584.0001471

LIMA, I. E. F. W. Determinação e simulação da evapotranspiração de uma bacia hidrográfica do cerrado. Dissertação (Mestrado em Ciências Agrárias) - Brasília: UnB. 2000. 
LIMA, J. E. F. W. Modelagem numérica do fluxo da água no solo e do escoamento de base em uma bacia experimental em área agrícola no Cerrado. Tese (Doutorado em Tecnologia Ambiental e Recursos Hídricos) - Brasília: Universidade de Brasília. 2010.

LOPES, T. R. ; MOURA, L. B.; NASCIMENTO, J. G.; JUNIOR, L S. F.; ZOLIN, C. A.; DUARTE, S. N.; FOLEGATTI, M. V. ; SANTOS, O. N. A. Priority areas for forest restoration aiming at the maintenance of water resources in a basin in the Cerrado/Amazon ecotone, Brazil. Journal of South American Earth Sciences, v. 101, p. 5-11, 2020. https://doi.org/10.1016/i.jsames.2020.102630

MARTINS, L. L. MARTINS, W. A.; MORAES, J. F. L.; JÚNIOR, M. J. P.; MARIA, I. C. Calibração hidrológica do modelo SWAT em bacia hidrográfica caracterizada pela expansão do cultivo da canade-açúcar. Revista Brasileira de Geografia Física, v. 13, n. 2, p. 576-594, abr. 2020. https://doi.org/10.26848/rbgf.v13.2.p576-594

MEDEIROS, I. C.; SILVA, R. M. Análise da erosão hídrica na região semiárida da Paraíba usando o modelo SWAT acoplado a um SIG. Geociências, v. 33, n. 3, p.457-471, 2014. http://www.ppegeo.igc.usp.br/index.php/GEOSP/article/view/7334

MORIASI, D. N.; GITAU, M. W.; PAI, N.; DAGGUPATI, P. Hydrologic and Water Quality Models: Performance Measures and Evaluation Criteria. Transactions of the ASABE, v. 58, n. 6, p. 17631785, 2015. https://doi.org/10.13031/trans.58.10715

MORIASI, D. N.; ARNOLD, J. G.; VAN LIEW, M. W.; BINGNER, R. L.; HARMEL, R. D.; VEITH, T. L. Model evaluation guidelines for systematic quantification of accuracy in watershed simulation. Transactions of the ASABE, v. 50, p. 885-900, may 2007. https://doi.org/10.13031/2013.23153

NASCIMENTO, J. M.; FRADE, T. G.; SILVA, R. M. Modelagem da resposta do escoamento em uma bacia do semiárido da Paraíba utilizando o modelo SWAT. Revista Brasileira de Geografia Física, v. 11, n.03, p. 1137-1150, 2018. https://doi.org/10.26848/rbgf.v11.3.p1137-1150

NASH, J.E.; SUTCLIFFE, J.V. River Flow Forecasting Through Conceptual Models Part I-A Discussion of Principles. Journal of Hydrology, v. 10, n. 3, p. 282-290, apr. 1970. https://doi.org/10.1016/0022-1694(70)90255-6

OLIVEIRA, V. A.; MELLO, C. R.; VIOLA, M. R.; SRINIVASAN, R. Assessment of climate change impacts on streamflow and hydropower potential in the headwater region of the Grande river basin, Southeastern Brazil. Int. J. Climatol., v. 37, p. 5005-5023, 2017. https://doi.org/10.1002/joc.5138

OLIVEIRA, V. A.; MELLO, C. R.; BESKOW, S.; VIOLA, M. R.; SRINIVASAN, R. Modeling the effects of climate change on hydrology and sediment load in a headwater basin in the Brazilian Cerrado biome. Esological Engineerng, v. 133, p. 20-31, 2019. https://doi.org/10.1016/j.ecoleng.2019.04.021

OTSUSCHI, C.; SOUZA, B. S. P.; PEREIRA, W. Escoamento superficial e fragmentação da vegetação remanescente nas bacias dos Lajeados São José e Passo dos Índios no Oeste do Estado de Santa Catarina, Brasil. Revista Caminhos de Geografia, v. 19, n. 66, p. 169-188, jun. 2018. http://dx.doi.org/10.14393/RCG196612

PINIEWSKI, M.; BIEGER, K.; MEHDI, B. Advancements in Soil and Water Assessment Tool (SWAT) for ecohydrological modelling and application. Ecohydrology \& Hydrobiology, v. 19, n. 2, p. 179181, april 2019. https://doi.org/10.1016/i.ecohyd.2019.05.001

QI, J.; WANG, Q.; ZHANG, X. Sobre o uso de dados meteorológicos NLDAS2 para modelagem hidrológica na Bacia do Alto Mississippi. Water, v. 11. n. 5, p. 1-18, may 2019. https://doi.org/10.3390/w11050960

RODRIGUES, E. L.; ELMIRO, E. L.; JACOBI, C. M.; LAMOUNIER, W. L. Aplicação do modelo SWAT na avaliação do consumo de água em áreas de florestas plantadas na bacia do Rio Pará, Alto São Francisco, em Minas Gerais. Sociedade \& Natureza, v. 27, n. 3, p. 485-500, set./dez. 2015. http://dx.doi.org/10.1590/1982-451320150309

RODRIGUES, E. L.; JACOBI, C. M.; FIGUEIREDO, J. E. C. Wildfires and their impact on the water supply of a large neotropical metropolis: A simulation approach. Science of The Total Environment, v. 651 , p. 1261-1271, 2019. https://doi.org/10.1016/j.scitotenv.2018.09.289 
SECRETARIA ESTADUAL DE INDÚSTRIA E COMÉRCIO DE GOIÁS - SIC DE GO. Modelagem, alimentação e edição do Mapa de Solos do Plano Diretor da Bacia do Rio Paranaíba, na escala 1:250.000, geração 01 de março de 2005.

SERRÃO, E. A. O.; SILVA, M. T.; FERREIRA, T. R.; SILVA, V. P. R.; SOUSA, F. S.; LIMA, A. M. M.; ATAIDE, L. C. P; WANZELER, R. T. S. Land use change scenarios and their effects on hydropower energy in the Amazon. Science of The Total Environment, v. 744, p. 1-17, 2020. https://doi.org/10.1016/i.scitotenv.2020.140981

SERTEL, E.; IMAMOGLU, M. Z.; CUCELOGLU, G.; ERTURK, A. Impacts of Land Cover/Use Changes on Hydrological Processes in a Rapidly Urbanizing Mid-latitude Water Supply Catchment. Water, v. 11, n. 5, p. 1-15, may 2019. https://doi.org/10.3390/w11051075

SILVA, R. M.; HENRIQUE, I. G. N.; GAZÉ, J. F. Simulação das mudanças de uso e ocupação do solo e seus efeitos nas características hidrossedimentológicas em uma bacia do bioma caatinga. Revista de Geografia (Recife), v. 35, n. 1, p. 158-179, 2018.

https://periodicos.ufpe.br/revistas/revistageografia/article/view/229325

SILVA, C. L; OLIVEIRA, C. A. S. Runoff measurement and prediction for a watershed under narutal vegetarion in central Brazil. Revsita brasileira de ciência do solo, v. 23, n. 3, p. 695-701, 1999. https://doi.org/10.1590/S0100-06831999000300024

SINGH, A.; IMTIYAZ, M.; ISAAC, R. K.; DENIS, D. M. Assessing the performance and uncertainty analysis of the SWAT and RBNN models for simulation of sediment yield in the Nagwa watershed, India. Hydrological Sciences Journal, v. 59, p. 351-364, 2014.

https://doi.org/10.1080/02626667.2013.872787

SISTEMA ESTADUAL DE GEOINFORMAÇÃO DE GOIÁS - SIEG. Downloads/SIG - Shapefiles. Disponível em: www.sieg.go.gov.br. Acesso em: 30 ago. 2018.

SUPERINTENDÊNCIA DE GEOLOGIA E MINERAÇÃO DE GOIÁS - SGM DE GO. Modelagem, alimentação e edição do Mapa de Solos do Plano Diretor da Bacia do Rio Paranaíba, na escala 1:250.000, geração 01 de março de 2005.

UNIVERSIDADE FEDERAL DE VIÇOSA (UFV). Mapa de Solos do Plano Diretor da Bacia do Rio Paranaíba, na escala 1:250.000, geração 01 de março de 2005.

VAN LIEW, M. W.; ARNOLD, J. G.; GARBRECHT, J. D. Hydrologic simulation on agricultural watersheds: choosing between two models. Transactions of the. ASAE, v.46, n. 6, p. 1539-1551, 2003. https://doi.org/10.13031/2013.15643

XUE, C.; CHEN, B.; WU, H. Parameter uncertainty analysis of surface flow and sediment yield in the Huolin Basin, China. Journal of Hydrologic Engineering, v. 19, p. 1224-1236, jun. 2014. https://doi.org/10.1061/(ASCE)HE.1943-5584.0000909

ZHANG, D.; CHEN, X.; YAO, H.; LIN, B. Improved calibration scheme of SWAT by separating wet and dry seasons. Ecological Modelling, v. 301, p. 54-61, Apr. 2015. https://doi.org/10.1016/..ecolmodel.2015.01.018

Recebido em: 25/10/2020

Aceito para publicação em: 30/12/2020 